\title{
In vitro and in vivo studies of a novel bacterial cellulose-based acellular bilayer nanocomposite scaffold for the repair of osteochondral defects
}

This article was published in the following Dove Press journal:

International Journal of Nanomedicine

I September 2017

Number of times this article has been viewed

\author{
Jyoti V Kumbhar' \\ Sachin H Jadhav ${ }^{2}$ \\ Dhananjay S Bodas' \\ Amruta Barhanpurkar-Naik ${ }^{3}$ \\ Mohan R Wani ${ }^{3}$ \\ Kishore M Paknikar' \\ Jyutika M Rajwade'
}

'Nanobioscience, ${ }^{2}$ Animal Sciences Division, Agharkar Research Institute, ${ }^{3}$ National Centre for Cell Science, Savitribai Phule Pune University, Pune, India
Correspondence: Kishore M Paknikar; Jyutika M Rajwade

Nanobioscience Group, Agharkar Research Institute, Pune 4I 1004, India

Tel +9l 2025653680

$\mathrm{Fax}+9 \mid 202565$ I542

Email kmpaknikar@aripune.org; jrajwade@aripune.org
Abstract: Bacterial cellulose (BC) is a naturally occurring nanofibrous biomaterial which exhibits unique physical properties and is amenable to chemical modifications. To explore whether this versatile material can be used in the treatment of osteochondral defects (OCD), we developed and characterized novel BC-based nanocomposite scaffolds, for example, BC-hydroxyapatite (BC-HA) and BC-glycosaminoglycans (BC-GAG) that mimic bone and cartilage, respectively. In vitro biocompatibility of BC-HA and BC-GAG scaffolds was established using osteosarcoma cells, human articular chondrocytes, and human adipose-derived mesenchymal stem cells. On subcutaneous implantation, the scaffolds allowed tissue ingrowth and induced no adverse immunological reactions suggesting excellent in vivo biocompatibility. Implantation of acellular bilayered scaffolds in OCD created in rat knees induced progressive regeneration of cartilage tissue, deposition of extracellular matrix, and regeneration of subchondral bone by the host cells. The results of micro-CT revealed that bone mineral density and ratio of bone volume to tissue volume were significantly higher in animals receiving bilayered scaffold as compared to the control animals. To the best of our knowledge, this study proves for the first time, the functional performance of acellular BC-based bilayered scaffolds. Thus, this strategy has great potential for clinical translation and can be used in repair of OCD.

Keywords: bacterial cellulose-hydroxyapatite, bacterial cellulose-glycosaminoglycan, osteochondral defect, stem cell differentiation, acellular bilayer scaffold

\section{Introduction}

Osteochondral defects (OCD) in joints are a leading cause of disability in the elderly population, post-menopausal women, and young athletes. ${ }^{1,2}$ Simultaneously, the cartilage and the underlying subchondral bone are damaged. Clinical intervention is essential to arrest cartilage degradation because the articular cartilage possesses limited natural healing capacity. As of now, autologous implantation of chondrocytes or osteochondral plugs is the only surgical treatment available for the restoration of the damaged tissue. ${ }^{3-5}$ The limitations associated with autologous implantation include the need for two surgeries, the extended period required for tissue recovery and maturation. ${ }^{4}$ As an alternative method, allogenous cell-based strategies are now emerging, which employ invasive techniques for the isolation of cells and their ex vivo expansion. However, these approaches have encountered significant barriers in therapeutic translation due to the rejection of cells, contamination due to pathogenic microorganisms, and tumorigenesis. Apart from these, difficulties in clinical adoption and regulatory approval are other factors that limit the use of cell-based strategies. ${ }^{6,7}$ 
Recently, acellular therapeutic strategy for tissue regeneration using biomaterials with or without signaling molecules has turned out to be a promising approach for the repair of OCD. This purpose warrants the development of bioactive scaffolds with spatially presented biological cues for repair of OCD. ${ }^{5-7}$ Although an ideal bioactive scaffold helps in the repair of OCD, its combination with microfracture therapy is thought to augment the healing process. ${ }^{8,9}$ Microfracture therapy involves drilling in the osteochondral lesion that aids in the recruitment of bone marrow stem cells. Eventually, stem cells colonize the scaffold and differentiate into respective cell types. ${ }^{4}$

Polymer-based scaffolds have been used to augment tissue regeneration by recapitulating a variety of physical cues of native tissue. ${ }^{10}$ Scaffolds in tissue engineering include several natural polymers, for example, silk, collagen, gelatin, dextran, and chitin, and synthetic polymers, for example, polylactide, polyglycolide, and poly(L-lactide-co-glycolide). ${ }^{11}$ The polymeric scaffolds in the form of hydrogels are known to promote cell infiltration and facilitate nutrient exchange. It would be highly advantageous if the hydrogel polymer possesses a nanoscale fibrous structure that mimics the native extracellular matrix supporting better adhesion, growth, and function of cells. Thus, a nanofibrous hydrogel matrix could form an excellent scaffold substitute in regenerative medicine. Moreover, the bioresorbable scaffolds that are designed to treat OCD should be able to withstand contraction forces arising due to tissue healing and physiological loading over a sufficient period. ${ }^{12}$ One such interesting nanoscale polymeric hydrogel could be "bacterial cellulose" (BC).

Recently, we have isolated a cellulose-producing bacterium and obtained BC using low-cost substrates. ${ }^{13} \mathrm{BC}$ is found to be suited for various biomedical applications because of its excellent physicochemical properties. ${ }^{14}$ Previous studies have explored the in vitro potential of $\mathrm{BC}$ as a scaffold for cartilage regeneration. ${ }^{15-18}$ Independent in vitro and in vivo studies have also been carried out to explore the osteogenic potential of BC and BC-hydroxyapatite (BC-HA) nanocomposites. ${ }^{19-22}$ The studies are indicative of the potential of $\mathrm{BC}$ as a biomaterial for the treatment of OCD.

In the osteochondral tissue, chondrocytes reside in the avascular chondral layer along with type II collagen and glycosaminoglycans (GAG). The osteoblasts exist in the vascularized subchondral bone layer which is made up of HA and type I collagen. Therefore, we hypothesized that BC-based acellular bilayer scaffolds which possess different features (eg, mechanical, chemical, or morphological properties) in each layer to satisfy the simultaneous regeneration of the chondral layer and the subchondral bone layer could be an ideal biomaterial for the repair of OCD. According to the tissue engineering approach, the host cells could then be directed to express the desired phenotype ultimately leading to the regeneration of functional tissues in vivo. ${ }^{23}$

The present study aimed at the development of new BC-based bilayer nanocomposite scaffolds and testing their biocompatibility both in vitro and in vivo. Furthermore, we also assessed the potential of these acellular nanocomposite scaffolds supplemented with or without growth factors in the repair of OCD in a rat model.

\section{Experimental section Production of BC}

The production of BC was carried out by the method described previously. ${ }^{13}$ Briefly, a single colony of Komagataeibacter hansenii MCM B-967 was inoculated into $100 \mathrm{~mL}$ pineapple peel medium and incubated at an ambient temperature $\left(25^{\circ} \mathrm{C} \pm 3^{\circ} \mathrm{C}\right)$ under static conditions. After 2 days of incubation, $10 \%$ of inoculum was transferred to $100 \mathrm{~mL}$ pineapple peel medium and further incubated for 7 days under static conditions at the ambient temperature $\left(25^{\circ} \mathrm{C} \pm 3^{\circ} \mathrm{C}\right)$. Floating $\mathrm{BC}$ pellicles formed at the air-liquid interface were harvested and purified.

\section{Synthesis of BC-HA nanocomposite scaffolds mimicking bone}

Scaffolds used in the present study were prepared by punching out sections of desired dimensions from $\mathrm{BC}$ pellicles using a cork borer. Nanocomposites of BC-HA were synthesized using simulated body fluid (SBF). ${ }^{24}$ For this, BC scaffolds were immersed in polyvinylpyrrolidone (PVP, $0.025 \mathrm{~g} \%$ in ultrapure water) solution at $30^{\circ} \mathrm{C}$ for 2 days. After washing with ultrapure water, the PVP-treated $\mathrm{BC}$ scaffolds were immersed in $0.1 \mathrm{~mol} / \mathrm{L} \mathrm{CaCl}_{2}$ solution at $37^{\circ} \mathrm{C}$ for 3 days, and finally, the PVP-modified and $\mathrm{Ca}^{2+}$-activated $\mathrm{BC}$ were soaked in a $1.5 \times \mathrm{SBF}$ at $37^{\circ} \mathrm{C}$ for 7 days.

\section{Synthesis of BC-GAG nanocomposite scaffolds mimicking cartilage}

BC-GAG nanocomposite scaffolds were prepared by incubation of BC scaffolds $(2 \times 2 \mathrm{~mm}$ dimensions, $\sim 50 \mathrm{mg}$ ) with chondroitin sulfate sodium salt $(0.5 \mathrm{~mL}$ of $10 \mathrm{mg} / \mathrm{mL}$ stock, Sigma-Aldrich Co., St Louis, MO, USA) by shaking continuously for 24 hours. The scaffolds were then washed 2-3 times with ultrapure water to remove the unbound chondroitin sulfate. The chondroitin sulfate bound to $\mathrm{BC}$ was estimated using 1,9-dimethylmethylene blue (DMMB) dye. ${ }^{25}$ 
Briefly, $6 \mathrm{~mL}$ of DMMB dye was added to each BC scaffold and vortexed vigorously for 30 minutes to promote complete complexation of bound chondroitin sulfate to the dye. The insoluble GAG-DMMB complex was separated by centrifugation $(12,000 \times g, 10$ minutes) and dissolved in $6 \mathrm{~mL}$ decomplexation solution $(50 \mathrm{mM}$ sodium acetate buffer, $\mathrm{pH}$ 6.8, containing 10\% n-propanol and $4 \mathrm{M}$ guanidine hydrochloride). Absorbance was measured at $656 \mathrm{~nm}$. Assays were performed in triplicate.

\section{Physico-chemical characterization of BC-HA and BC-GAG composites}

For the preliminary morphological analysis of composite formation, BC-HA and BC-GAG composites were stained with Alizarin red S (ARS) and DMMB, respectively. Furthermore, detailed morphology was examined using scanning electron microscopy. For this, the BC-HA and BC-GAG composites were freeze dried (Martin Christ, Osterode am Harz, Germany) and coated with gold using an ion sputter coater and imaged using EVO MA15 microscope (Carl Zeiss Meditec AG, Jena, Germany) operated at $20 \mathrm{kV}$.

A nanomechanical test instrument(TI 950 TriboIndenter ${ }^{\mathrm{TM}}$; Hysitron, Minneapolis, MN, USA) was used for the assessment of nanomechanical properties of the $\mathrm{BC}$ nanocomposites. BC, BC-HA, and BC-GAG samples were air dried and cut into small pieces $\sim 1 \mathrm{~mm}$ thick. The resultant samples were flat and glued to the sample holder. Load-controlled quasistatic nanoindentation experiments were made using a trapezoidal loading curve on $\mathrm{BC}, \mathrm{BC}-\mathrm{GAG}$, and $\mathrm{BC}-\mathrm{HA}$ samples at the peak load of 45,30 , and $20 \mu \mathrm{N}$, respectively, using Piezo Automation technique. Each experiment comprised 5 seconds loading time, 5 seconds hold time, and 5 seconds unloading time. Indentations ( $\mathrm{n}=20$ per sample) were carried out using Berkovich Diamond Probe (Ei is $1,140 \mathrm{GPa}$, and vi is 0.07$)$. The data on applied load (P) and indenter displacement $(\mathrm{h})$ into the sample were recorded continuously. The sample hardness $(\mathrm{H})$ and reduced elastic modulus (Er) were then calculated from the load versus displacement curve and averaged together.

To ascertain the surface functionalization, Fourier transform infrared (FTIR) spectra of BC, BC-HA, BC-GAG, and chondroitin sulfate sodium salt were obtained over the range of 500-4,000 $\mathrm{cm}^{-1}$ using powdered forms of the samples (Spectrum 2000; PerkinElmer Inc., Waltham, MA, USA) at ambient temperature.

X-ray diffraction (XRD) studies were carried out to determine the degree of purity and crystallinity of the nanocomposites. For this, samples were freeze dried and powdered and diffractograms were obtained using desktop X-ray diffractometer (Rigaku Miniflex II, Tokyo, Japan). The XRD patterns were obtained at $\mathrm{Cu} \mathrm{K} \alpha$ radiation of $1.54 \AA$, generated at a voltage of $40 \mathrm{kV}$ and current of $40 \mathrm{~mA}$. The diffraction angle ranged from $10.0^{\circ}$ to $60^{\circ}$ with a step size of $0.033^{\circ}$.

\section{In vitro biocompatibility of BC nanocomposite scaffolds}

The in vitro biocompatibility of BC nanocomposite scaffolds was assessed using an established cell line, for example, SaOS-2 cells (ATCC ${ }^{\circledR}$ HTB-85TM, Passage 47) and primary human articular chondrocytes (hAC, Passage 7, obtained from National Centre for Cell Science, Pune, India). Prior to cell seeding and to facilitate adhesion, the BC-HA and BCGAG scaffolds ( $5 \mathrm{~mm}$ diameter $\times 1 \mathrm{~mm}$ height) were soaked in Dulbecco's Modified Eagle's Medium (DMEM; Thermo Fisher Scientific, Waltham, MA, USA) supplemented with $10 \%$ fetal bovine serum (FBS) (Thermo Fisher Scientific) and $1 \%$ antibiotic-antimycotic solution (Himedia Labs, Mumbai, India) for 18 hours. Maintaining a seeding density of $10^{4}$ cells per scaffold per well, incubation was carried out at $37^{\circ} \mathrm{C}$ with $5 \% \mathrm{CO}_{2}$ and $95 \%$ relative humidity. Testing of $\mathrm{BC}-\mathrm{HA}$ and $\mathrm{BC}-\mathrm{GAG}$ scaffolds for the growth of SaOS-2 and hAC, respectively, was carried out with native $\mathrm{BC}$ as a control.

\section{Cell attachment and proliferation}

For visualizing cell attachment, the cellularized scaffolds were washed gently with phosphate-buffered saline (PBS) and fixed in $3.7 \%$ paraformaldehyde in $0.1 \mathrm{M} \mathrm{PBS} \mathrm{(pH} \mathrm{7.2)}$ for 15 minutes at ambient temperature. After fixation, scaffolds were washed with PBS and processed further for fluorescence labeling of the actin cytoskeleton and cell nuclei. Briefly, permeabilization of cells with $0.2 \%$ Triton X-100 in PBS for 20 seconds was followed by blocking with $2 \%$ bovine serum albumin for 5 minutes. Scaffolds were washed gently with cold PBS and stained with a 1:1 solution of DAPI (4',6-diamidino-2-phenylindole, dihydrochloride) for staining nuclei and rhodamine phalloidin for actin cytoskeleton (Thermo Fisher Scientific) for 30 minutes in the dark. Scaffolds were observed under fluorescence microscope (Eclipse E 200; Nikon Corporation, Tokyo, Japan).

Cell proliferation was assessed using Prestoblue ${ }^{\circledR}$ cell viability reagent (Thermo Fisher Scientific), in which $100 \mu \mathrm{L}$ of dye was added to the wells at each time point and incubated for 6 hours. Fluorescence intensity was recorded at an excitation wavelength of $530 \mathrm{~nm}$ and an emission wavelength of $645 \mathrm{~nm}$ using microplate reader (Synergy HT; BioTek, Winooski, VT, USA). The experiment was performed in triplicate, and average 
fluorescence values of control samples (scaffolds without cells) were subtracted from each of the experimental wells.

\section{Alkaline phosphatase (AP) live staining}

SaOS-2-seeded BC and BC-HA scaffolds were visualized for AP-positive cells at 4-day time point. For staining, growth medium from the cultures was removed, and scaffolds were washed with DMEM for 2-3 minutes. The AP stain (Thermo Fisher Scientific) was diluted according to the manufacturer's instructions, and the scaffolds were stained and washed. Fresh DMEM was added before the visualization of cells under a fluorescence microscope using a standard fluorescein isothiocyanate filter.

\section{Mineralization assay and estimation of sulfated glycosaminoglycans (sGAG)}

Mineralization was estimated on days 7, 14, and 21. Cellseeded scaffolds were washed with PBS and fixed in $10 \%(\mathrm{v} / \mathrm{v})$ formaldehyde (Sigma-Aldrich Co.) at ambient temperature for 15 minutes. The scaffolds were then washed with excess distilled water before the addition of $1 \mathrm{~mL}$ of $40 \mathrm{mM}$ ARS stain (pH 4.1) per well and incubated for 2 minutes. After aspiration of the unincorporated dye, the wells were washed four times with $4 \mathrm{~mL}$ distilled water while shaking for 5 minutes. The plates were then left at an angle for 2 minutes to facilitate the removal of excess water and stored at $-20^{\circ} \mathrm{C}$ before dye extraction. ${ }^{26}$

Mineralization was quantitated using the ARS stain (dissolved with $100 \mu \mathrm{L}$ cetyl pyridinium chloride [CPC] for 1 hour under gentle agitation). CPC from each scaffold well was transferred to a 96-well plate and diluted with $100 \mu \mathrm{L}$ of distilled water. The absorbance of ARS was determined at $562 \mathrm{~nm}$, and the concentration was determined against a standard plot using various dilutions of ARS. ${ }^{26,27}$ sGAG content in scaffolds was quantified using the DMMB dyebinding assay" as described in "Synthesis of BC-GAG nanocomposite scaffolds mimicking cartilage" section.

\section{Assessment of differentiation of human adipose tissue-derived mesenchymal stem cells (hATMSCs) in the presence of BC nanocomposite scaffolds}

The suitability of the nanocomposite scaffolds for differentiation was evaluated using hATMSC. These cells were obtained from National Centre for Cell Science, Pune. For this, BC, BC-HA, and BC-GAG scaffolds were presoaked into 96-well plates ( $\mathrm{n}=6$ per scaffold) in alpha Modified Eagle Medium ( $\alpha$-MEM, Sigma-Aldrich Co.) supplemented with 10\% FBS (Thermo Fisher Scientific). The seeding density of hATMSC was $10^{4}$ cells per scaffold. Cell-seeded scaffolds were maintained in an incubator at $37^{\circ} \mathrm{C}$ with $5 \%$ $\mathrm{CO}_{2}$ and $95 \%$ relative humidity, and the medium was changed every alternate day. On days 0,7 , and 10, staining of scaffolds using LIVE/DEAD ${ }^{\circledR}$ cell imaging kit (Thermo Fisher Scientific) was performed. Freshly prepared stain was added to scaffold samples, incubated for 15 minutes at $20^{\circ} \mathrm{C}-25^{\circ} \mathrm{C}$, and then the cells were imaged. Cell proliferation was evaluated using Prestoblue cell viability assay at varying time points, for example, days $0,3,7,10$, and 14 .

For osteogenic induction, the hATMSCs were cultivated in $\alpha$-MEM containing $10 \% \mathrm{FBS}, 100 \mathrm{nmol} / \mathrm{L}$ dexamethasone, $10 \mathrm{mM} \beta$-glycerol phosphate, and $50 \mathrm{mg} / \mathrm{mL}$ L-ascorbic acid. Mineralization assay was performed 21 and 28 days after seeding, using formalin fixed scaffolds, for example, $\mathrm{BC}$ in osteogenic $(\mathrm{O})$ medium, $\mathrm{BC}$ in control $(\mathrm{C})$ medium, BC-HA $(\mathrm{O})$, and $\mathrm{BC}-\mathrm{HA}(\mathrm{C})$. Cells seeded in 96-well tissue culture plates ( $\mathrm{O}$ and $\mathrm{C}$ media) served as control. In addition, AP activity was estimated as an early marker of osteoblastic differentiation. hATMSCs were cultured on BC, BC-HA scaffolds, and in tissue culture plate (positive control) in $\mathrm{O}$ and $\mathrm{C}$ media. On days 4 and 7, cells were detached from the scaffolds using trypsin/ethylenediamine tetra-acetic acid (EDTA) (Thermo Fisher Scientific). The cells were collected by centrifugation and lysed with $0.1 \%$ radioimmunoassay precipitation buffer by incubating for 60 minutes on ice. The cell lysates were prepared by centrifugation for 20 minutes at 12,000 rpm and $4^{\circ} \mathrm{C}$. The protein content of the cell lysates was estimated using Lowry's method. Cell lysate $(50 \mu \mathrm{L})$ was incubated for $60 \mathrm{~min}$ at $37^{\circ} \mathrm{C}$ with $150 \mu \mathrm{L}$ of assay buffer containing $10 \mathrm{mM}$ p-nitrophenylphosphate (nPP). The addition of $100 \mu \mathrm{L}$ of $0.5 \mathrm{M}$ sodium hydroxide stopped the reaction, and absorbance was read at $405 \mathrm{~nm}$. AP activity was calculated as micromoles nPP hydrolyzed per minute per microgram of protein.

Differentiation of hATMSC into chondrocytes was studied using BC and BC-GAG scaffolds in chondrogenic (Ch) medium consisting of DMEM supplemented with $10 \mathrm{ng} \mathrm{mL} \mathrm{m}^{-1}$ transforming growth factor- $\beta$ (TGF- $\left.\beta\right)$, ITS +1 (100× liquid media supplement), 0.1 M sodium pyruvate, $35 \mathrm{mM}$ proline, $17 \mathrm{mM}$ ascorbic acid, and $1 \mathrm{mM}$ dexamethasone (all from Sigma-Aldrich Co.). The conventional pellet system set up in $15 \mathrm{~mL}$ conical bottom tubes served as positive control. Aliquots of $2 \times 10^{5}$ cells $/ 0.5 \mathrm{~mL}$ were centrifuged at $500 \times g$ for 5 minutes to form soft pellets and cultured in the serum-free Ch medium, without (control) or with growth factor supplementation (test). Native BC and BC-GAG scaffolds seeded with hATMSC but cultured in DMEM served as internal control. The pellets and the cell-seeded scaffolds were maintained for up to 28 days with medium change after 
every second day. sGAG were quantified at day 28 according to the method described above.

\section{In vivo studies}

All the in vivo experiments were performed with the approval of the Institutional Animal Ethics Committee of Agharkar Research Institute (ARI/IAEC/2014/CNB-03 and 06). Animal handling procedures were carried out as per guidelines defined by the Committee for Control and Supervision of Experiments on Animals, Ministry of Environment and Forests, Government of India. The animals were caged individually, provided with food and water ad libitum, appropriate temperature $\left(23^{\circ} \mathrm{C} \pm 1^{\circ} \mathrm{C}\right)$, relative humidity $55 \% \pm 5 \%$ and were kept under 14-hour light/10-hour dark cycle.

\section{In vivo biocompatibility}

Wistar rats with an average body weight of 150-200 g were used in the present study. The study consisted of four groups ( $n=6$ per group) corresponding to three kinds of scaffolds, for example, BC, BC-HA, and BC-GAG. One group that underwent surgery but did not receive scaffold served as sham-operated control.

Sterile surgical procedures were followed during implantation (Figure S1A). For anesthetization, animals were injected intraperitoneally with Ketamine $\mathrm{HCl}(80 \mathrm{mg} / \mathrm{kg})$ and xylazine $(10 \mathrm{mg} / \mathrm{kg})$. After surface disinfection, a 2-3 cm incision was made, and sterilized scaffolds were inserted into a subcutaneous pocket created in the region corresponding to the lower thoracic vertebrae. The incision was closed by using nylon sutures followed by the application of a topical antiseptic. Postoperative care was ensured by the administration of ceftriaxone $(10 \mathrm{mg} / \mathrm{kg})$ and dexamethasone $(10 \mathrm{mg} / \mathrm{kg})$ intramuscularly for 3 days. Each rat was then caged individually for 45 days and monitored for local reactions such as erythema, inflammation, water, and food intake and weekly body weight.

Post-implantation, blood was collected from the retroorbital plexus of rats on days 15 and 45. Hematological parameters were determined using a hematology analyzer (BC-1800 Victor; Mindray, Indonesia) and differential leucocyte count (DLC) was performed by microscopic observation of blood smears. Levels of inflammatory cytokines, for example, interleukin-1 (IL-1) and tumor necrosis factor- $\alpha$ (TNF- $\alpha$ ) were assessed by using ELISA (Abcam, UK). At the end of 45 days, rats were sacrificed by carbon dioxide asphyxiation; the scaffolds along with the surrounding tissues were excised and fixed in $10 \%$ buffered formalin. After dissection of the animals, vital organs such as spleen, kidney, and heart were excised and weighed.
For histological analysis, formalin-fixed scaffolds with the surrounding tissue were embedded in paraffin, and sections ( $10 \mu \mathrm{m}$ thickness) were prepared using a microtome. Ladewig's, hematoxylin and eosin, and ARS staining of tissue sections were performed as per standard protocol. Sections were then examined using an optical microscope (Nikon Eclipse E200; Nikon Corporation, Tokyo, Japan). Excised scaffolds were also visualized using a scanning electron microscopy (EVO MA15 microscope; Carl Zeiss Meditec AG).

\section{Assessment of functional performance of BC nanocomposite scaffolds} Study design and creation of $O C D$

A total of 48 male Wistar rats weighing 150-200 g were selected to induce OCD. The animals were randomly divided into four groups ( $\mathrm{n}=12$ animals per group), for example, control defect (no scaffold), BC scaffold, bilayer scaffold (representing BC-HA and BC-GAG placed one over the other), and bilayer scaffold supplemented with growth factors (recombinant human BMP-2 [Thermo Fisher Scientific], source Escherichia coli; recombinant human TGF- $\beta 3$ [Sigma-Aldrich Co.] expressed in HEK 293 cells). The total amount of growth factors loaded onto the scaffolds was $1 \mu \mathrm{g}$ BMP-2 and 5 ng TGF- $\beta 3 .{ }^{28}$ Intraperitoneally injected mixture of ketamine $\mathrm{HCl}(80 \mathrm{mg} / \mathrm{Kg})$ and xylazine $(10 \mathrm{mg} / \mathrm{Kg})$ served as an anesthetic for animals. OCD ( $1 \mathrm{~mm}$ diameter $\times 3 \mathrm{~mm}$ depth) were created in the patellar groove of the knee joints using both a hand drill and a dental burr (Figure S1B-G). The muscle incision was closed using cat gut sutures, and the skin incision was closed using nylon sutures followed by the application of a topical antiseptic. Another 12 animals that underwent the same surgical procedure without induction of OCD served as sham-operated control. In the case of BC scaffolds, a single layer of BC scaffold was inserted into the defect. For the bilayer and bilayer + growth factor (GF) scaffold group, BC-HA scaffold layer was inserted first, followed by the BC-GAG scaffold layer and press-fitted one over the other. Postoperative care was ensured by the administration of ceftriaxone $(10 \mathrm{mg} / \mathrm{kg})$ and dexamethasone $(10 \mathrm{mg} / \mathrm{kg})$ intramuscularly for 3 days. Each animal was then caged individually for up to 90 days. No external support was provided to the knees of the experimental animals. Thus, the site of implant borne full weight while the animals moved.

Six animals from each group were sacrificed at 1 month, and the remaining six were sacrificed at 3 months by carbon dioxide asphyxiation. Knees were excised, fixed in $10 \%$ buffered formalin, and evaluated according to the International Cartilage Repair Society (ICRS) macroscopic assessment scores for cartilage repair. ${ }^{29}$ 


\section{Micro-CT $(\mu \mathrm{CT})$}

For $\mu \mathrm{CT}$ analysis, the formalin-fixed bones were cleaned to remove the attached muscle tissue. The samples were analyzed using the Micro-CT scanner (GAMMA MEDICA-IDEAS FLEX TM Triumph TM Pre-Clinical Imaging System) at Advanced Center for Treatment, Research and Education in Cancer, Mumbai, India. The scan settings were: X-ray voltage $60 \mathrm{keV}$, X-ray current $140 \mu \mathrm{A}$, and projection 1024 . The scans were then reconstructed to create the three dimensional (3D) geometry by using GEHC Microview software (v.2.2; GE Healthcare, Toronto, Canada). After scanning and reconstruction, the image obtained in the sagittal plane was analyzed. A region of interest (ROI) was selected entirely covering the defect area and bone mineral density (BMD) and bone volume to tissue volume ratio (BV/TV, \%) in the same selected ROI was calculated (GEHC Microview).

\section{Histological staining}

Knees were decalcified in EDTA solution, dehydrated in a graded series of acetone, and embedded in paraffin. For Safranin O staining, sections were stained with Weigert's hematoxylin solution for 10 minutes and rinsed in running tap water. Then they were placed in Fast green for 5 minutes, followed by quick rinsing in $1 \%$ acetic acid solution, stained with $0.1 \%$ Safranin $\mathrm{O}$ solution for 5 minutes and dehydrated in $100 \%$ alcohol. The histological sections were analyzed and graded by using the articular cartilage repair scoring system. ${ }^{30}$ The least scores are indicative of good repair of OCD. The actual scoring used in the present study is provided in Table $\mathrm{S} 1$.

\section{Statistical analysis}

The values were expressed as mean \pm SEM. The data were analyzed with one-way analysis of variance, followed by Bonferroni multiple comparison post hoc test. The statistical analysis was performed by using GraphPad Prism 6.0 (GraphPad Software, Inc., La Jolla, CA, USA). A $P$-value of $<0.05$ was considered statistically significant.

\section{Results}

\section{Synthesis and physico-chemical characterization of BC-HA and BC-GAG nanocomposites}

Formation of BC-HA and BC-GAG nanocomposites is represented schematically in Figure 1A. Preliminary confirmation of the formation of BC-HA nanocomposites was obtained using ARS dye which specifically stains calcium deposits. The microscopic images of BC scaffolds showed smooth and even surfaces, while the surface of BC-HA composite scaffolds appeared rough and granular, probably due to the deposition of HA crystals. Scanning electron microscopic images revealed the presence of cuboidal crystals $(\sim 1 \mu \mathrm{m})$ formed on the surface of BC (Figure 1B). Upon staining with DMMB dye, BC-GAG nanocomposites showed a purple coloration in contrast to the blue color of the native $\mathrm{BC}$ (Figure 1A). The GAG-DMMB complex was purple colored, and the blue color could be due to the deposition of DMMB on BC. The surface of BC-GAG composites appeared smooth probably due to the deposition of GAG. In some areas, characteristic features of native BC (Figure 1C) were observed, indicating nonuniform GAG deposition.

The nanomechanical characteristics of $\mathrm{BC}$ nanocomposites were determined in comparison with $\mathrm{BC}$ because the aim was to use them as scaffolds for the repair of OCD. The in situ scanning probe microscopy image of the residual indent showing residual impression for BC, BC-GAG, and BC-HA show that $B C$ and $B C-G A G$ scaffolds have a smooth surface (Figure 1D-F). Figure S2A-C shows the data on applied load (P) and indenter displacement (h) into the sample. The peak loading force on $\mathrm{BC}$ was the maximum $(45 \mu \mathrm{N})$, while it was the least for BC-HA nanocomposite $(20 \mu \mathrm{N})$. The load versus displacement curve (Figure 1G-I) was used to calculate the sample hardness $(\mathrm{H})$ and reduced elastic modulus $(\mathrm{Er})$. The average elastic modulus was calculated to be $3.75,3.49$, and 2.49 GPa for BC, BC-GAG, and BC-HA films, respectively. The calculated hardness was $0.1770,0.1798$, and $0.1161 \mathrm{GPa}$ for BC, BC-G, and BC-HA films, respectively.

The FTIR spectrum of BC-HA (Figure 2A) showed peaks at 1,409 and $600 \mathrm{~cm}^{-1}$ corresponding to carbonate and phosphate groups, respectively. The peak at $1,050 \mathrm{~cm}^{-1}$ corresponds to the stretching mode of phosphate. Moreover, a red shift for peak at $3,600 \mathrm{~cm}^{-1}$ could be assigned to strong intramolecular hydrogen bonding between the hydroxyl groups of BC and apatite. FTIR spectrum of BCGAG (Figure 2B) composite showed peaks at 3,335 $\mathrm{cm}^{-1}$ which indicate $\mathrm{O}-\mathrm{H}$ and $\mathrm{N}-\mathrm{H}$ stretching vibration, peak at $2,984 \mathrm{~cm}^{-1}$ indicates absorption due to $\mathrm{C}-\mathrm{H}$ stretching of the methyl or methylene group. Furthermore, the absorption at $1,651 \mathrm{~cm}^{-1}$ could be ascribed to the presence of amide bonds, and peaks at 1,422 and $1,369 \mathrm{~cm}^{-1}$ were indicative of coupling of $\mathrm{CO}$ stretch vibration and $\mathrm{OH}$ variable angle vibration. Absorption band observed at $1,253 \mathrm{~cm}^{-1}$ could be attributed to the stretching vibration of $\mathrm{SO}_{4}{ }^{2-}$ bond, and peak at $1,039 \mathrm{~cm}^{-1}$ to stretch the vibrations of $\mathrm{CO}$. The peaks at 3,000-2,900 and $1,071 \mathrm{~cm}^{-1}$ correspond to $\mathrm{C}-\mathrm{H}$ stretching and $\mathrm{C}-\mathrm{O}$ stretching, respectively. 
A

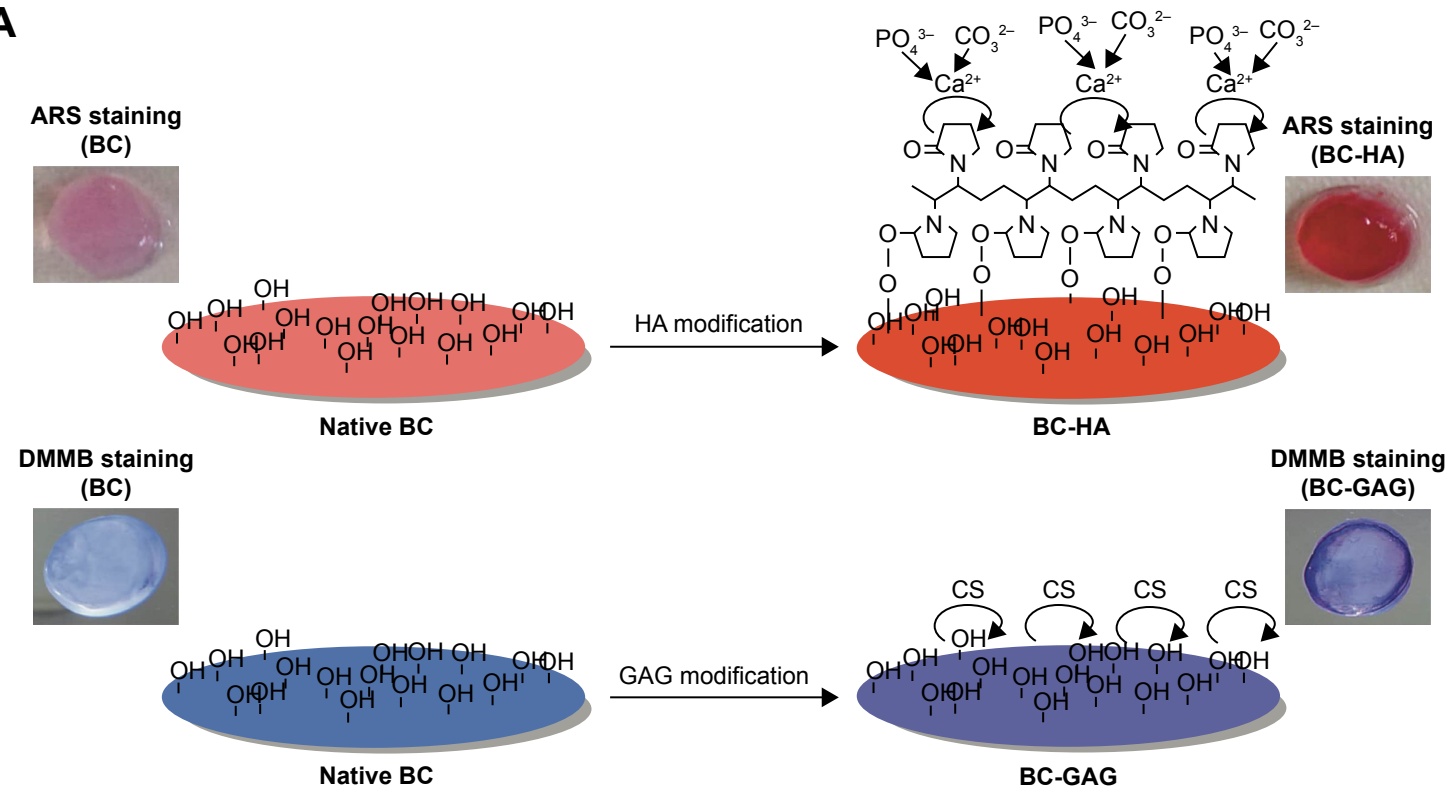

B
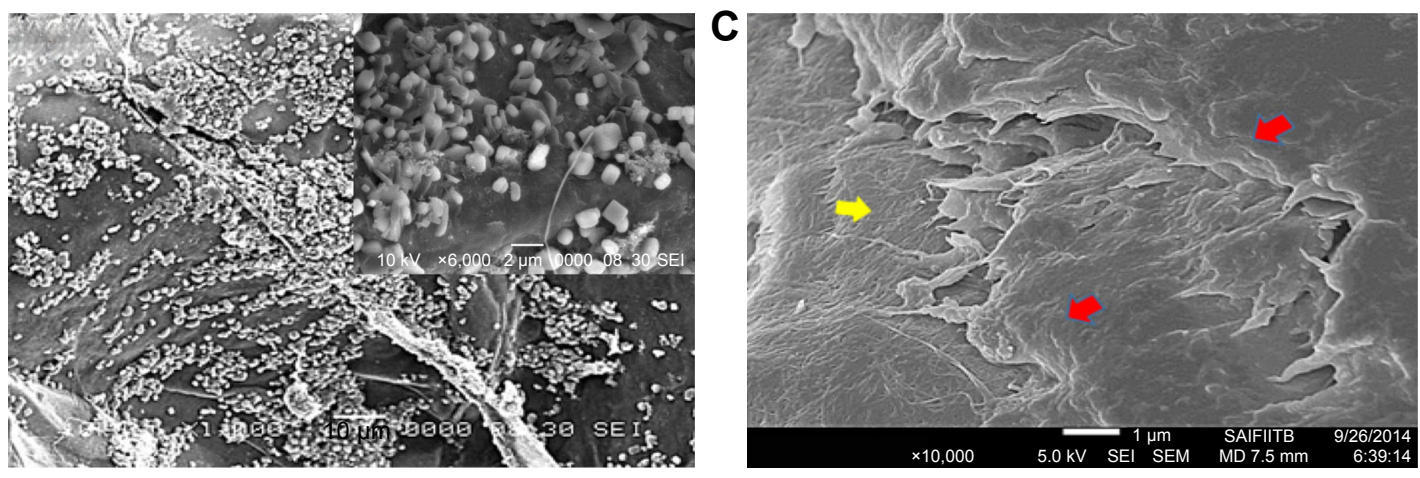

D

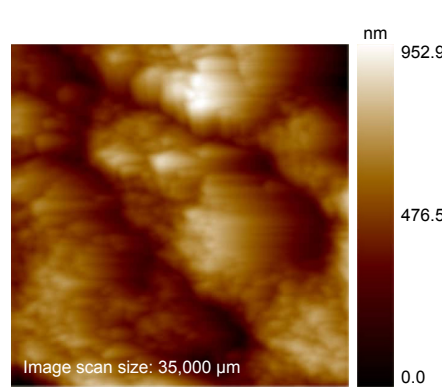

E

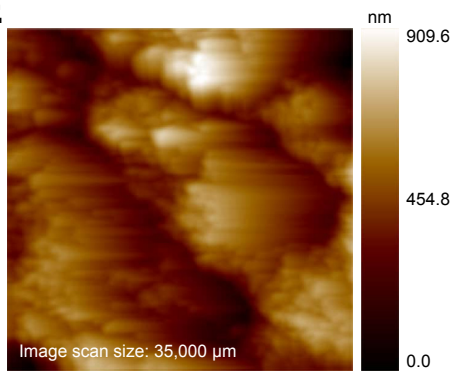

F

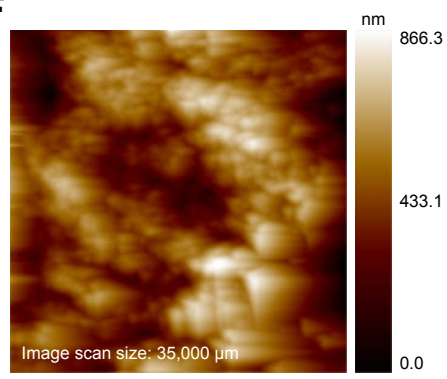

G

H

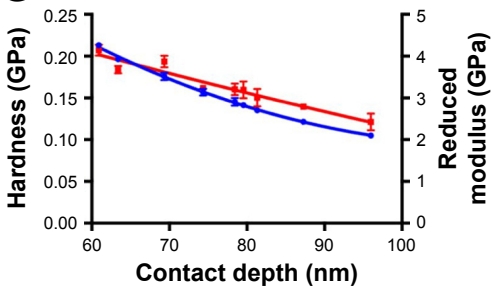

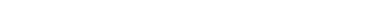
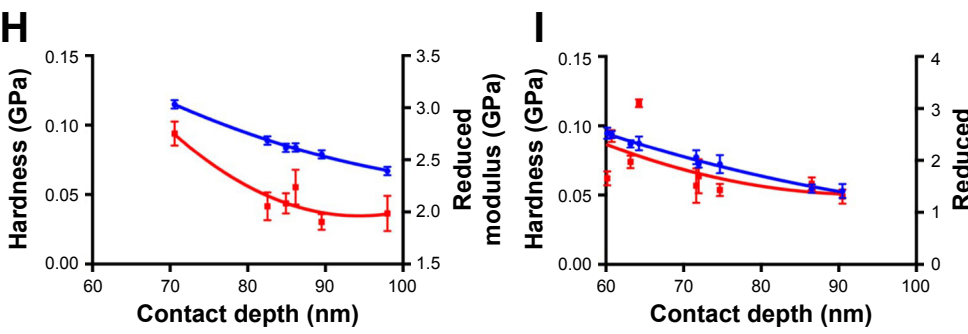

$\longrightarrow$ Hardness (GPa) $\rightarrow$ Reduced modulus (GPa)

Figure I (A) Schematic representation for the synthesis of bacterial cellulose-hydroxyapatite and bacterial cellulose-glycosaminoglycan nanocomposite scaffolds. SEM images of (B) BC-HA nanocomposite showing deposition of hydroxyapatite crystals. The crystalites of hydroxyapatite are evident in the inset. (C) BC-GAG nanocomposite scaffolds; red arrows indicate the chondroitin sulfate adsorbed onto the surface of BC (yellow arrow). In situ SPM images of residual indent showing residual impression for (D) BC, (E) BC-GAG, and (F) BC-HA. The sample hardness and reduced elastic modulus (Er) was calculated from the load versus displacement curve, for the nanocomposite scaffolds. (G) The contact force was $45 \mu \mathrm{N}$ for BC; (H) $30 \mu \mathrm{N}$ for BC-GAG; and (I) $20 \mu \mathrm{N}$ for BC-HA were observed. Indentations ( $\mathrm{n}=20$ per sample) were carried out using Berkovich Diamond Probe (Ei is I, $140 \mathrm{GPa}$ and vi is 0.07 ).

Abbreviations: ARS, Alizarin red S; BC, bacterial cellulose; BC-GAG, BC-glycosaminoglycans; BC-HA, BC-hydroxyapatite; DMMB, dimethylmethylene blue. 

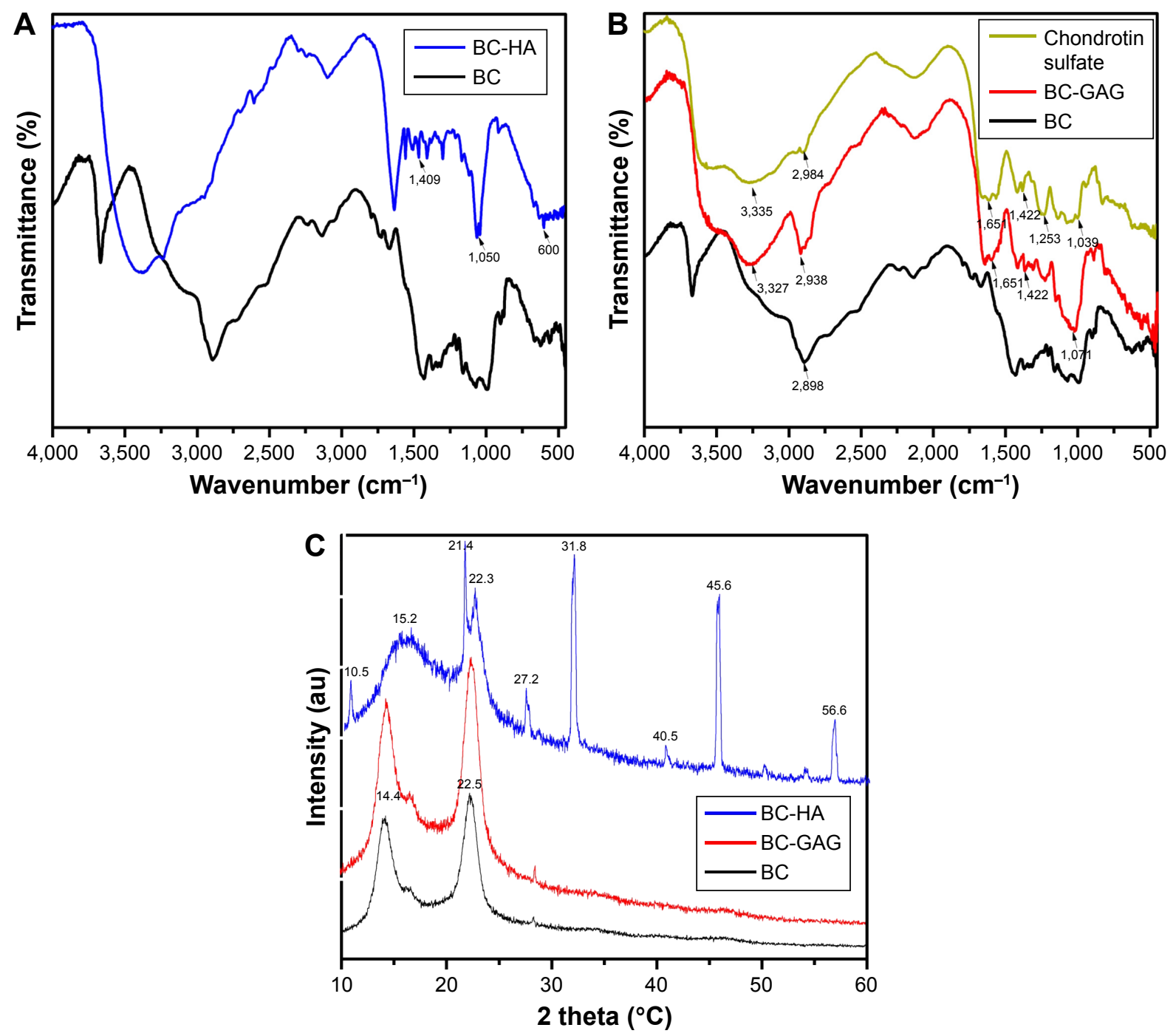

Figure 2 (A) FTIR spectra of BC (black line) and BC-HA (blue line) nanocomposites. (B) FTIR spectra of BC (black line), BC-GAG nanocomposite (red line), and chondroitin sulfate (green line). (C) X-ray diffraction analysis of BC, BC-GAG and BC-HA nanocomposites.

Abbreviations: BC, bacterial cellulose; BC-GAG, BC-glycosaminoglycans; BC-HA, BC-hydroxyapatite; FTIR, Fourier transform infrared.

Figure 2C shows X-ray diffractograms of native $\mathrm{BC}$ which revealed the presence of characteristic peaks at $14.4^{\circ}$ and $22.5^{\circ}$, which are assigned to the (101) and (002) crystallographic planes. In case of BC-HA composite, there was a slight shift in the peak from $14.4^{\circ}$ to $15.2^{\circ}$. Furthermore, broadening and decreased peak intensity was observed at $15.2^{\circ}$. In addition to the characteristic peak at $22.3^{\circ}$, a sharp peak at $21.4^{\circ}$ was observed. In addition, peaks at $10.6^{\circ}, 27.2^{\circ}$, $31.8^{\circ}, 40.5^{\circ}, 45.6^{\circ}$, and $56.6^{\circ}$ were observed. These changes might have occurred due to the deposition of HA.

\section{In vitro biocompatibility of $B C$ nanocomposite scaffolds}

First, the ability of the modified and unmodified scaffolds to support cell adhesion and growth was assessed. For this, in vitro studies using SaOS-2 cells and hAC were performed. Fluorescence microscopic images (Figure S3A) of cell-seeded BC and BC-HA scaffolds at day 8 revealed a higher number of cells on BC-HA scaffolds. SaOS-2 cells appeared to have a rounded morphology on BC scaffolds, whereas they appeared more elongated and well spread on BC-HA scaffolds. Adherent cells can be stained using the AP live stain without loss of proliferation. The dye allows visualization of live cells while being present on the scaffold. Staining of BC-HA scaffolds on day 4 (Figure S3B) revealed a higher number of AP-positive cells as compared to native $\mathrm{BC}$. As evidenced by the cell viability assay, both $\mathrm{BC}$ and $\mathrm{BC}-\mathrm{HA}$ scaffolds supported adhesion and growth of SaOS-2 cells. At days 2 and 8, BC-HA scaffolds showed significantly higher proliferation of SaOS-2 cells when 
compared to $\mathrm{BC}(P<0.05$; Figure $\mathrm{S} 3 \mathrm{C})$. In comparison with $\mathrm{BC}$, mineralization was also substantially higher on $\mathrm{BC}-\mathrm{HA}$ scaffolds at all the time points, that is, days 7,14 , and 21 $(P<0.001$; Figure S3D).

The microscopic analysis showed that the primary chondrocytes spread well on both the BC and BC-GAG scaffolds (Figure S3E). In fact, the Prestoblue cell viability assay indicated higher proliferation of primary chondrocytes on BC-GAG scaffolds on day 8 (Figure S3F). The results of the DMMB assay for the quantitative estimation of sGAG clearly showed that the levels of GAG $(\mu \mathrm{g})$ produced by chondrocytes on BC-GAG scaffolds were higher (2.24 \pm 0.35$)$ than BC scaffolds (1.48 \pm 0.33$)$. Results indicate that the GAG formation was indeed comparable to positive control (1.89 \pm 0.08 ; Figure $\mathrm{S} 3 \mathrm{G})$.

\section{Assessment of osteo- and chondro- genic differentiation of hATMSC in the presence of $B C$ nanocomposite scaffolds}

Figure $3 \mathrm{~A}$ is a fluorescence microscopic image of hATMSCseeded scaffolds after performing live/dead staining. It is evident that after initial attachment onto the scaffolds, the hATMSC grow, proliferate, and remain viable on all the scaffolds. In fact, none of the scaffolds showed the presence of dead cells. Furthermore, it was observed that cells proliferated well on all the three scaffolds up to the time points assessed that is day 14 . On day 3 , the proliferation in control as well as in all scaffold groups was similar. While at days 7, 10, and 14, BC-HA and BC-GAG scaffolds showed better cell proliferation compared to $\mathrm{BC}$ scaffold and tissue culture control $(P<0.001$ vs control, Figure 3B). Osteogenic medium favored mineralization, which is evident from the data on ARS staining of scaffolds. The red color was more pronounced in case of BC-HA scaffolds at both the time points, that is, days 21 and 28 (Figure 3D).

Quantitative estimation of calcium using the cetylpyridinium chloride method was done to support the visual observations. Mineralization was expressed in terms of calcium content $(\mathrm{mM}) /$ scaffold in the CPC assay. Data indicated that among the scaffold groups, BC-HA (O) group showed significantly higher calcium deposition compared to $\mathrm{BC}(\mathrm{C}), \mathrm{BC}(\mathrm{O})$, and $\mathrm{BC}-\mathrm{HA}(\mathrm{C})$ groups at both the time points (Figure 3C). One of the early indicators of osteoblastic differentiation is expression of AP. AP activity was highest in hATMSC cultured in tissue culture plate in the presence of $\mathrm{O}$ medium. The measurement of AP activity was used to substantiate the functional activity of the hATMSC on the scaffolds. On day 4, hATMSC cultured on BC-HA scaffolds supplemented with osteogenic medium showed significantly higher AP levels, and the same trend was observed on day 7 also. Cells cultured on BC scaffolds in osteogenic medium also showed good differentiation as evidenced by the expression of AP (Figure 3E). The results of AP activity suggest that modification of scaffolds with HA and growth in osteogenic medium indeed promoted the differentiation of hATMSC to osteoblastic lineage.

Estimation of GAG levels determined the differentiation of hATMSC to chondrocytes. The hATMSC cultured in the conical tube (pellet) showed highest GAG levels (3.25 $\mu \mathrm{g} / \mathrm{scaffold}$ ). The presence of growth factor (in $\mathrm{Ch}$ medium) favored differentiation of hATMSC, as evidenced by the amount of sGAGs produced on native BC. Interestingly, hATMSC cultured on BC-GAG scaffolds in the presence of control medium (devoid of growth factors) showed significantly higher sGAG formation compared to BC (C) group (Figure 3F). These findings suggest that the miniscule quantities of GAG associated with the $\mathrm{BC}$ provide the necessary biological cues for the cells to undergo differentiation into the $\mathrm{Ch}$ lineage.

\section{In vivo biocompatibility of $B C$ nanocomposite scaffolds}

\section{Gross observations}

All the experimental animals survived during the study period, and no infection and surgery-related complications occurred in either scaffold or sham control groups. There were no signs of inflammation such as erythema, redness, swelling, or pus formation at or around the implant site. The body weight of all the animals increased every week during the experimental period, and there was no significant difference between the body weight of sham control group and the scaffold implanted groups (data not shown). After sacrificing the animals, the weights of vital organs such as liver, kidney, heart, and spleen were found to be in the normal range (data not shown). Upon explantation, scaffolds were present and appeared to integrate very well with the surrounding tissue in all the scaffold groups. However, grossly the BC-HA scaffolds seemed to be more whitish compared to control $\mathrm{BC}$ and BC-GAG scaffolds (data not shown).

\section{Inflammation}

We assessed the blood hematology parameters such as $\mathrm{Hb}$, $\mathrm{RBC}, \mathrm{WBC}$, hematocrit, mean corpuscular volume, mean corpuscular hemoglobin, DLC and cytokines at days 15 and 45. The hematology values have been listed in Table S2 and were found 
A
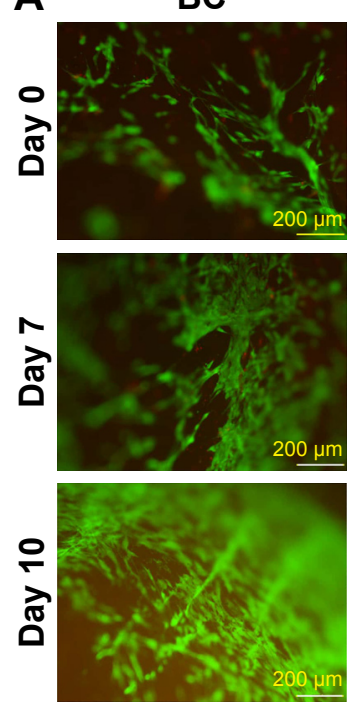

C

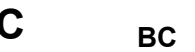

(C)

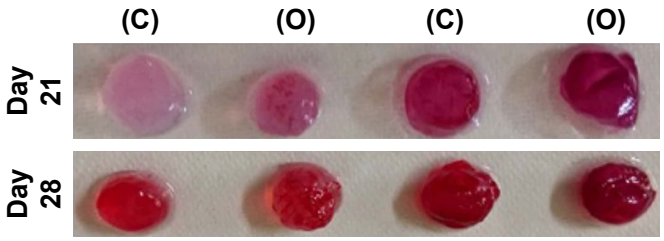

E

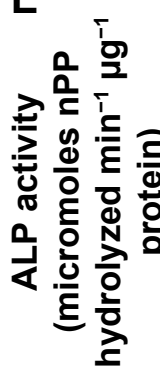

BC-HA
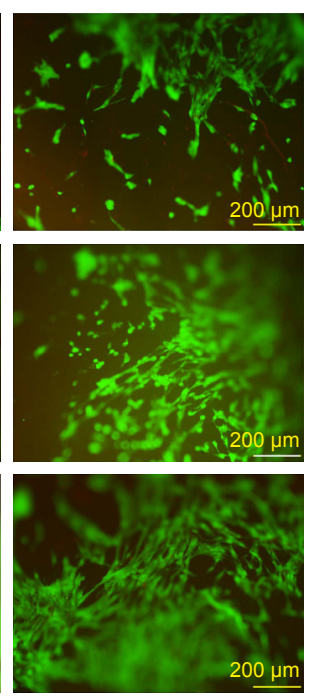

BC-GAG
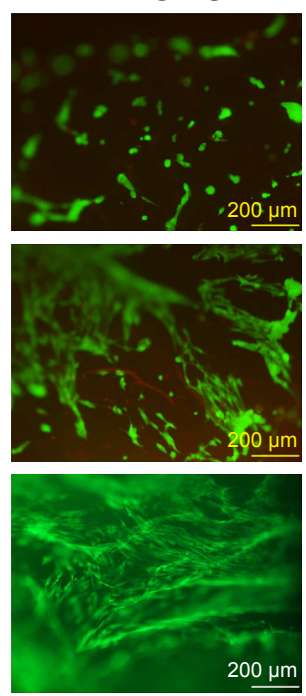

$200 \mu \mathrm{m}$

Tc
(C)

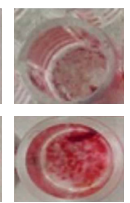

B
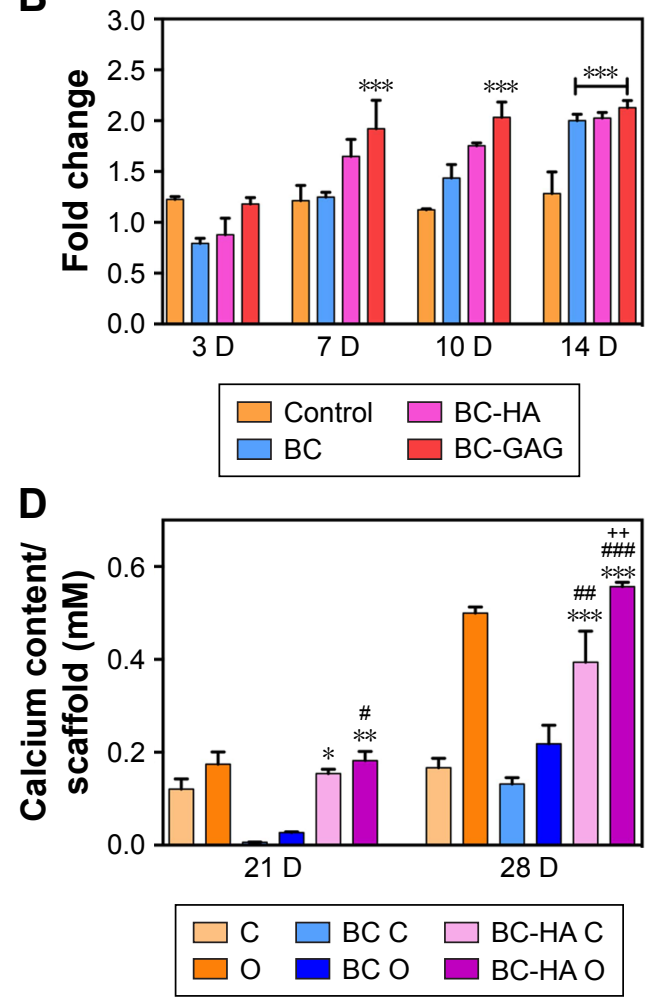

(0)

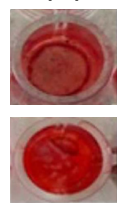

$\mathbf{F}$

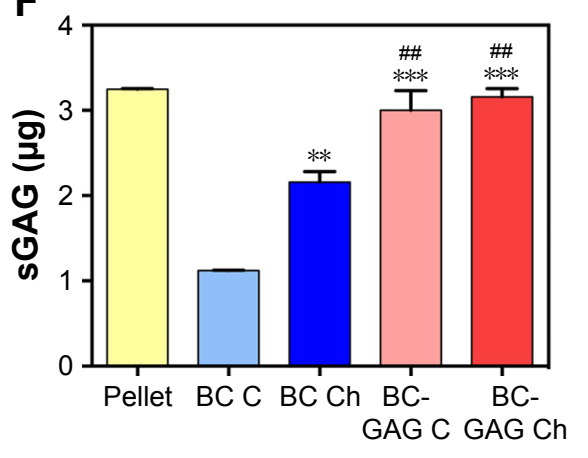

Figure 3 Mesenchymal stem cell differentiation study.

Notes: (A) Live-dead staining of hATMSCs on BC, BC-HA, and BC-GAG scaffolds. (B) Proliferation of hATMSCs on BC, BC-HA, and BC-GAG scaffolds, mean \pm SEM ( $n=3$ ), $* * * P<0.00$ I versus control. (C) Qualitative (alizarin red S staining). The scaffold and the 96 -well plate image are 5 mm in diameter. (D) Quantitative (cetyl pyridinium method) assessment of mineralization on $B C$ and $B C-H A$ scaffolds in both control and osteogenic medium, respectively, mean $\pm S E M(n=3$ ), $* P<0.05$, $* * P<0.0 \mathrm{I}, * * * P<0.00 \mathrm{I}$ versus $B C$ $C$ group; ${ }^{\# P}<0.05,{ }^{\# P}<0.01,{ }^{\#} P<0.00$ I versus $B C O$ group; ${ }^{+} P<0.01$ versus $B C-H A C$ group. (E) Alkaline phosphatase activity of hATMSCs on $B C$ and $B C$-HA scaffolds,

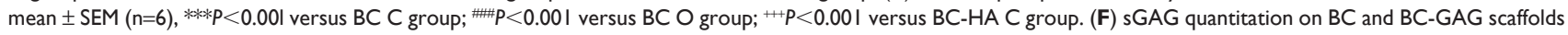
in control and chondrogenic medium. Values expressed as mean \pm SEM $(n=3), * * P<0.01$ and $* * * P<0.00$ I versus $B C$ control, ${ }^{\#} P<0.01$ versus $B C$ Ch scaffolds.

Abbreviations: BC, bacterial cellulose; BC-GAG, BC-glycosaminoglycans; BC-HA, BC-hydroxyapatite; hATMSC, human adipose tissue-derived mesenchymal stem cell; SEM, standard error of mean; sGAG, sulfated glycosaminoglycans.

to be comparable to the sham control group and did not vary significantly within the scaffold groups, suggesting the absence of surgery-related or implant-related infections. We observed no significant differences in the differential leukocyte counts (data not shown) in the scaffold groups compared to shamoperated control. The levels of IL- 1 and TNF- $\alpha$ were very low and comparable to sham control group (Table S2). These results suggest no systemic adverse reaction of scaffolds to rats.

\section{Histology of tissue surrounding the scaffolds}

The optical microscopy-based histological evaluation of tissues surrounding the implant provides morphological and 
pathological analyses. The H\&E staining of skin section surrounding scaffolds as well as in sham-operated control showed normal skin histology (Figure S4). Skin sections showed an intact cornified layer on top, beneath which stratified squamous epithelial cells, hair follicles, sebaceous glands, blood vessels, and bundles of loose collagen fibers were observed. Adverse reactions such as encapsulation, necrosis, scar formation, and inflammation were not detected for any of the scaffolds groups. These findings suggest acceptance and good integration with host tissue and rules out any long chronic adverse effect of implanted scaffold.

\section{Tissue scaffold interaction}

The scaffolds were stained using H\&E and differential Ladewig's trichrome staining to elucidate the tissue scaffold interaction. In Ladewig's staining, collagen stains blue, erythrocytes and muscle tissue stain yellow or orange, and cytoplasm and nuclei appear red and dark blue, respectively. BC scaffold (Figure 4A and B) showed host fibroblast infiltration, collagen deposition, and blood vessel formation. In the case of BC-HA (Figure 4E and F) and BC-GAG (Figure 4I and J), observations were similar. The formation of
RBC-perfused microvascular networks, host fibroblast infiltration, and ECM deposition suggest the integration of biomaterial with the surrounding tissue. ARS staining confirmed the deposition of calcium as indicated by an intense red staining on BC-HA scaffolds (Figure 4H) as against BC and BC-GAG scaffolds (Figure 4D and L).

The scanning electron microscopy analysis of explanted BC (Figure 4C) and BC-GAG (Figure 4K) scaffolds showed cell attachment and deposition of collagen-like materials on the scaffold surface, whereas on BC-HA scaffolds (Figure 4G), nodule formation was observed, probably due to mineral deposition. Due to surface similarities of different kinds of cells, it was difficult to divulge detailed information about cell types adhered onto scaffolds.

\section{Assessment of functional performance of $B C$ nanocomposite scaffolds}

\section{Gross observations}

All the Wistar rats used in the study survived during the experimental period until sacrifice. After surgery, no groups showed any signs of infection or immunological rejection. Furthermore, the opposing articulating surfaces showed no
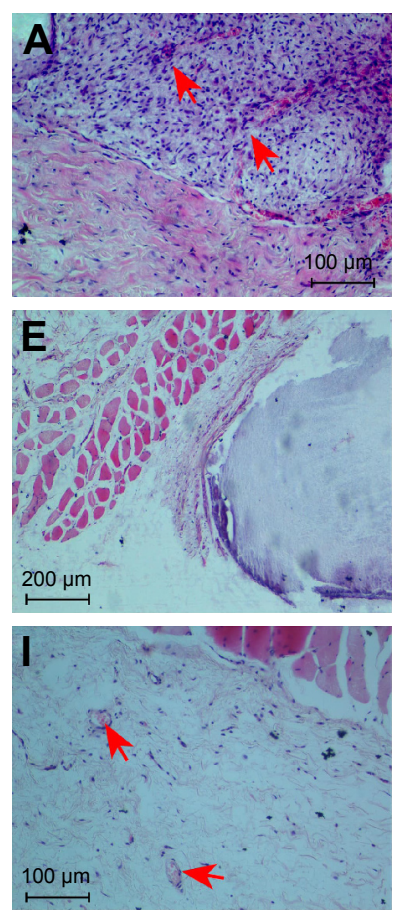
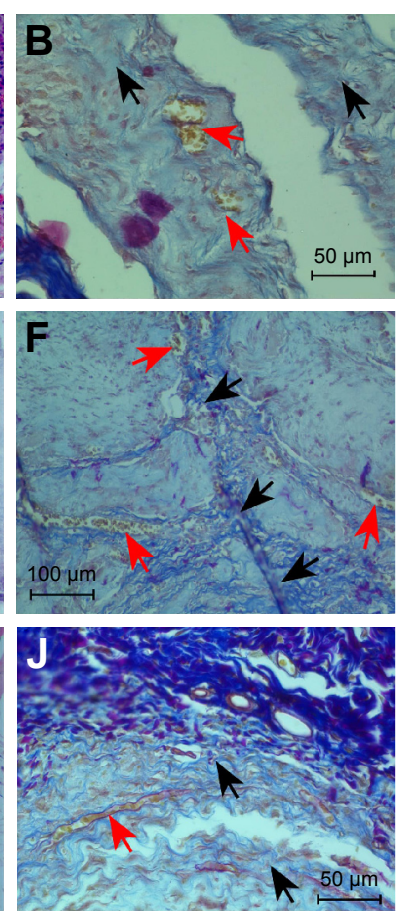
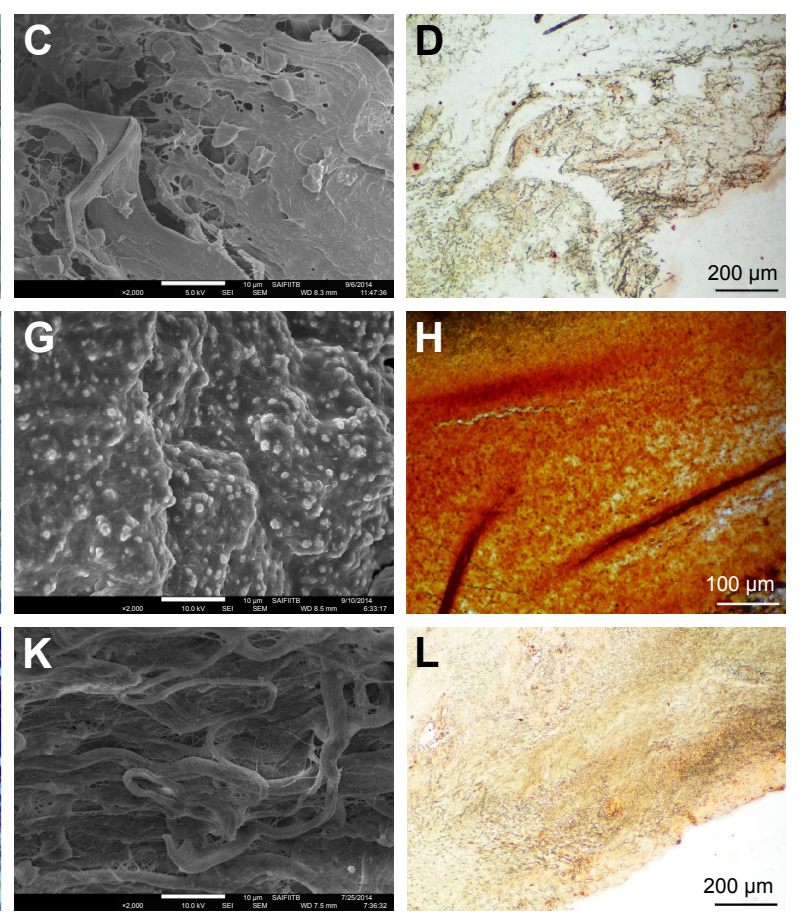

Figure 4 Histological analysis of BC, BC-HA, and BC-GAG scaffolds.

Notes: H\&E staining of skin sections in (A) BC, (E) BC-HA, and (I) BC-GAG scaffold groups at 45 days post implantation. Ladewig's staining of skin sections in (B) BC, (F) BC-HA, and (J) BC-GAG scaffold groups at 45 days post implantation (red arrows indicate blood vessel formation and black arrows indicate collagen that is stained blue), Scanning electron microscopy imaging of skin excised $(\mathbf{C})$ BC, $(\mathbf{G})$ BC-HA (K), and BC-GAG scaffolds showing cells on BC and BC-GAG scaffolds and mineral deposits on $B C-H A$ scaffold at 45 days post implantation, alizarin red $S$ staining of skin excised (D) BC, (H) BC-HA, and (L) BC-GAG scaffolds showing intense red staining in BC-HA scaffolds due to calcium deposition at 45 days post implantation. Magnification of images A, B, D, E, F, H, I, J, L is I0X and that of C, G, K is 2,000X.

Abbreviations: BC, bacterial cellulose; BC-GAG, BC-glycosaminoglycans; BC-HA, BC-hydroxyapatite. 
abrasions and no inflammation of the synovial membranes and other joint tissues at both 1 and 3 months. At 1-month post-operation (Figure 5A), the control defect group exhibited clearly recognizable defect margins. The defect surfaces were significantly depressed but were covered with a semitransparent white sparse fibrous tissue. In the BC scaffold group, the edges of the defects were clearly seen and covered with incomplete neo-tissue. However, the bilayer and the bilayer + GF groups showed good surface regularity. There was an absence of visible cracks or fissures, which are often seen in OCD repaired with polymers. Firm cartilage-like tissue filled the defect completely, which appeared similar in color and texture to the surrounding articular surface.

At 3 months, all the control defect knee explants showed fibrous tissue in the defects without cartilage-like tissue regeneration. In the $\mathrm{BC}$ scaffold group, the defect surfaces were slightly depressed but were covered significantly with neo-tissue better than at 1 month. The bilayer and bilayer + GF groups showed the repaired tissue well integrated with the adjacent native cartilage and regenerated tissue appeared concave in shape.

Semi-quantitative evaluation of the quality of the repair tissue in different groups at 1 and 3 months post-implantation was performed from ICRS gross scoring (Figure 5B). At both the time points, assessment of the degree of defect repair, integration of border zone and macroscopic appearance was carried out. At 1 and 3 months, the gross scores in BC control group were not significant as compared to control defect group. In the case of bilayer group, the scores $(2.6 \pm 0.57$ at 1 month and $1.6 \pm 0.57$ at 3 months) were significantly better as compared to control defect $(P<0.05)$. Similarly, bilayer + GF group showed significantly higher scoring $(2.00 \pm 1.00$ at 1 month, $P<0.01)$ and $(0.67 \pm 0.58$ at 3 months, $P<0.001)$ as compared to control defect group. The bilayer $+\mathrm{GF}$ group also showed better scoring as compared to BC control group. The results indicate faster healing of defects in bilayer and bilayer + GF group as compared to native BC and control defect groups.

\section{Histological observations}

At 1 month, in the control defect group, the defect was visible and contained sparse fibrous tissue or fibrocartilage. Visualization of implanted scaffold was possible in the control BC group, and the surface of the defect showed a thin layer of the fibrous tissue. Hyaline-like cartilage on the edges or interior of the defect was observed in the animals receiving the bilayer scaffold as evidenced by safranin $\mathrm{O}$ staining; and scaffold was visible in the defect area. Interestingly, the bilayer + GF group showed signs of resorption of the scaffold and the formation of neocartilage and bone (Figure 6A). At 3 months, there was no sign of cartilage regeneration in the control defect group and defect appeared to be completely filled with fibrous tissue. In the native BC scaffold, a mixture of fibrocartilage and cartilage-like tissues seemed to fill the defect and small bony islands in the scaffold were visible. Both the bilayer and the bilayer + GF scaffold group showed complete neocartilage and neobone formation at the defect site. Moreover, full integration of the neotissue with the surrounding healthy tissue was noted. The bilayer group showed the presence of a small portion of the scaffold, whereas the scaffold had completely resorbed in the bilayer + GF group. Histological analyses using safranine O-Fast green staining corroborate the gross morphological observations.

The histological scoring system was used to evaluate the healing of the defect site. Host tissue scores in the bilayer and bilayer + GF groups with control defect and BC scaffold groups (Figure 6B) showed significant differences in the mean scores of matrix, cell morphology, matrix staining, surface regularity of cartilage, thickness of cartilage, and tissue integration $(P<0.01$ and $P<0.001)$.

\section{$\mu \mathrm{CT}$ evaluation of subchondral bone}

The formation of subchondral bone was evaluated noninvasively using microcomputed tomography. $\mu \mathrm{CT}$ images in sagittal planes that passed through the center of the defect were chosen for analysis. As seen in Figure 7A, at 1 month, the defect was clearly visible in the control defect group, whereas, at 3 months, partial filling was observed. Bone formation in the BC scaffold group was weak at 1 month, and even at 3 months, subchondral bone regeneration in the defect area was incomplete. In the subchondral bone of bilayer and bilayer + GF groups, at 1 month, signs of restoration appeared, and at 3 months, thick and flat regenerated subchondral bone was visible.

Assessment of the BV to TV ratio at 1 month indicated that the BV/TV\% was significantly higher in bilayer + GF (32.14 \pm 1.32$)$ group compared to the control defect group (24.99 $\pm 2.01, P<0.01)$. In bilayer $+\mathrm{GF}$ group at 3 months, the $\mathrm{BV} / \mathrm{TV} \%$ was highest (37.31 \pm 0.85 ) compared to other groups $(P<0.001$ vs control defect group, $P<0.001$ vs BC scaffold group, $P<0.05$ vs bilayer group). In fact, it was comparable to the sham control group $(42.81 \pm 2.45)$ (Figure $7 \mathrm{~B})$. The BMD (Figure 7C) also showed the same trend with significantly higher values in the bilayer group (186.31 \pm 10.34 and 

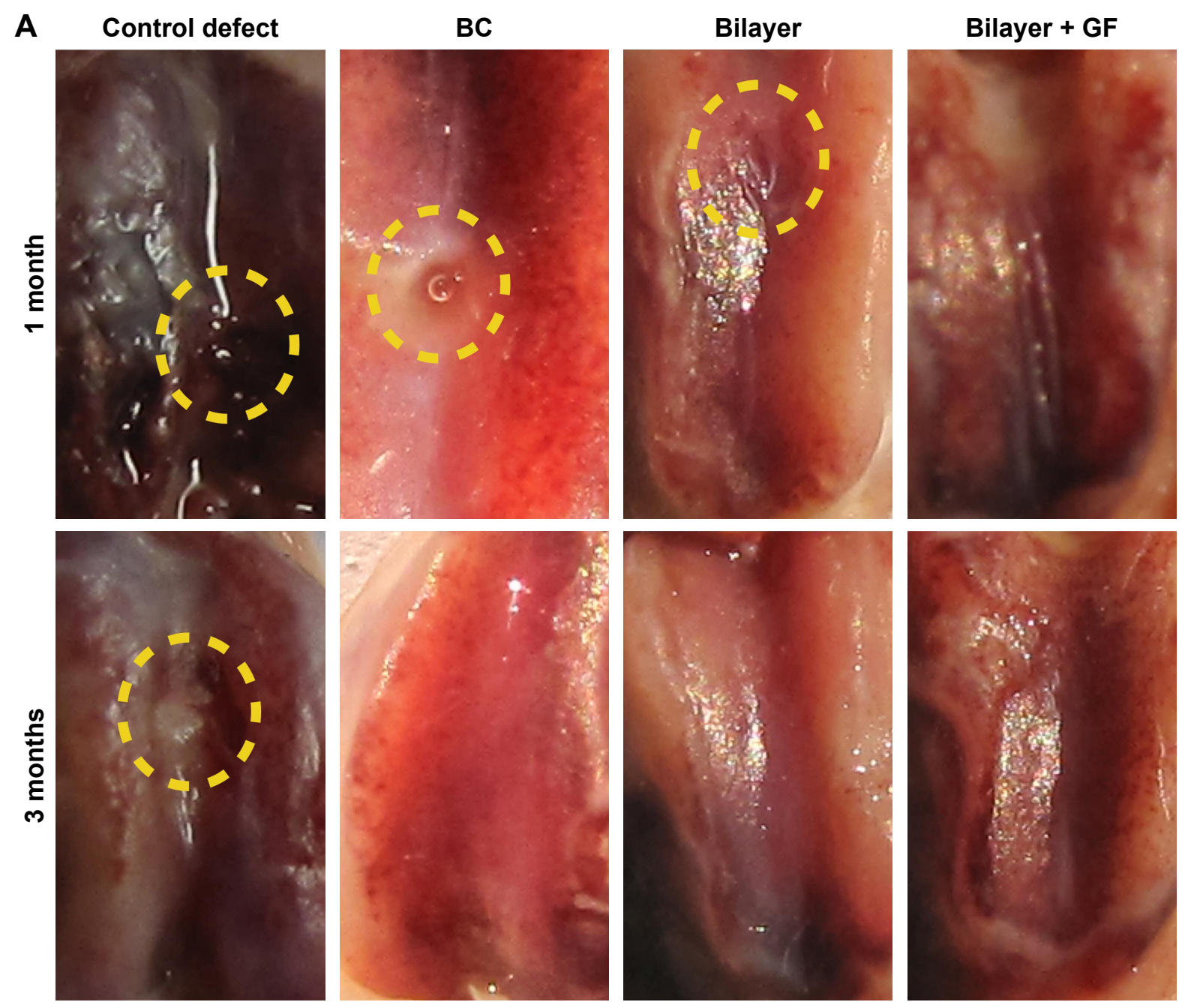

B

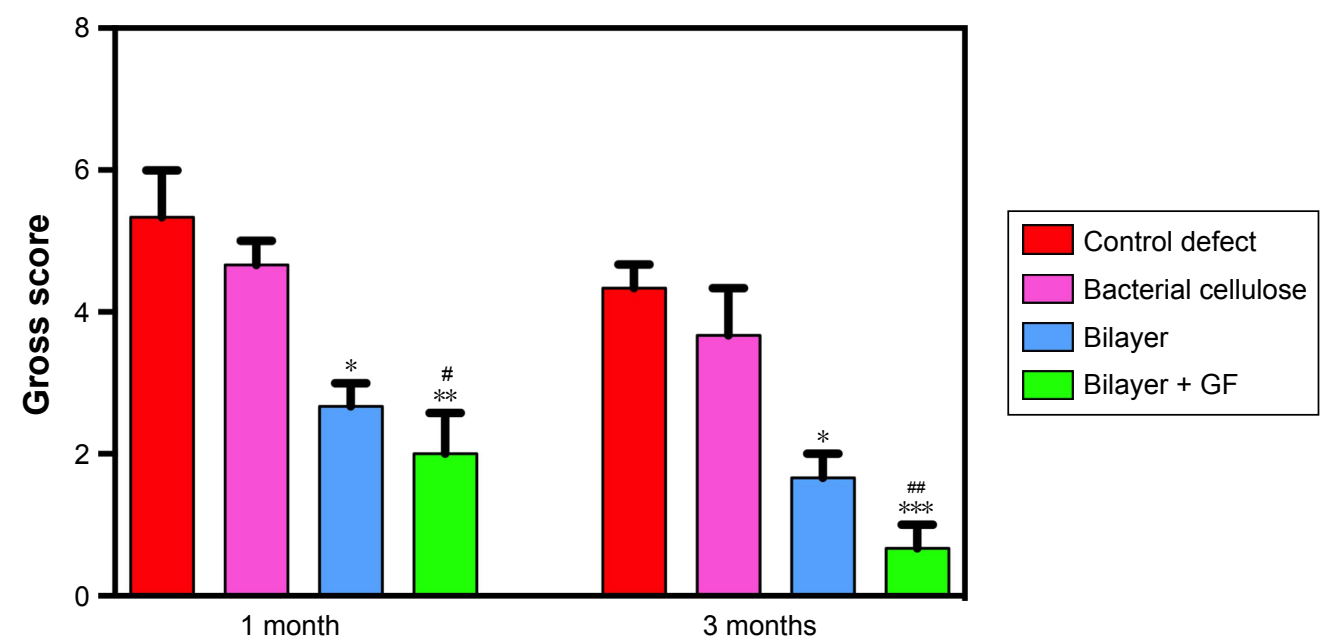

Figure 5 (A) Gross morphological observations of the excised knee showing the patellar groove in various experimental groups at I and 3 months post scaffold implantation (yellow circles show osteochondral defect sites); (B) ICRS gross scoring in various experimental groups at I and 3 months post scaffold implantation. Assessment scales were 0 to 3 for surface texture of repaired tissue, area of defect filled (\%) and graft-recipient tissue integration. The minimum and maximum scores obtained were 0 and 9 , where 0 indicates normal hyaline cartilage and 9 indicates $<50 \%$ cartilage formation. Values expressed as mean $\pm S E M(n=6)$, $* * P<0.01$ versus control defect group. ${ }^{\#} P<0.05$, \# $P<0.01$ versus $B C$ scaffold. $* * * P<0.001$. $* P<0.05$.

Abbreviations: BC, bacterial cellulose; GF, growth factor; ICRS, International Cartilage Repair Society; SEM, standard error of mean. 


\section{A}

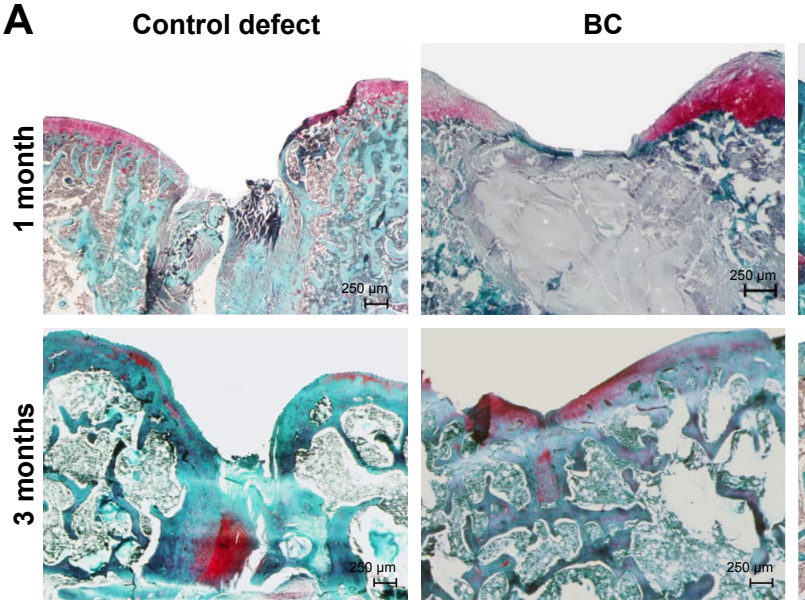

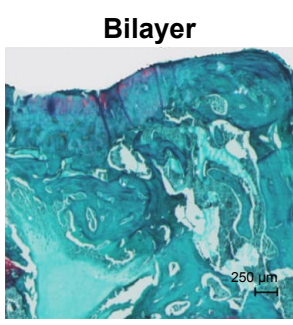
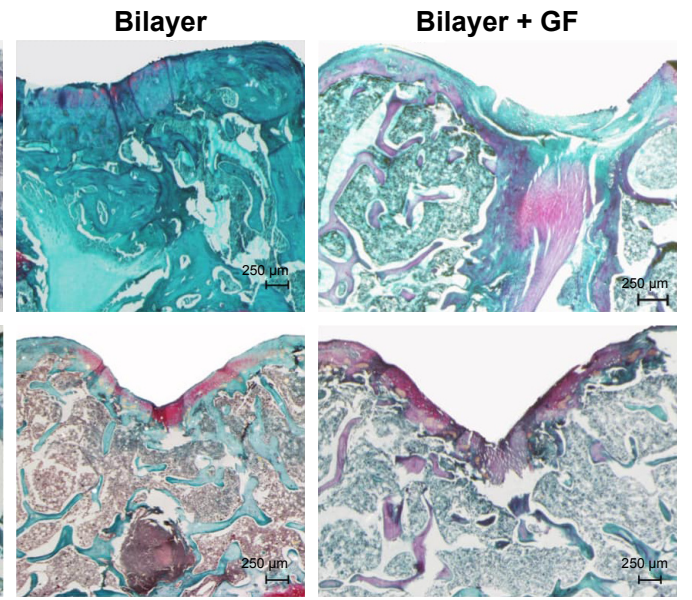

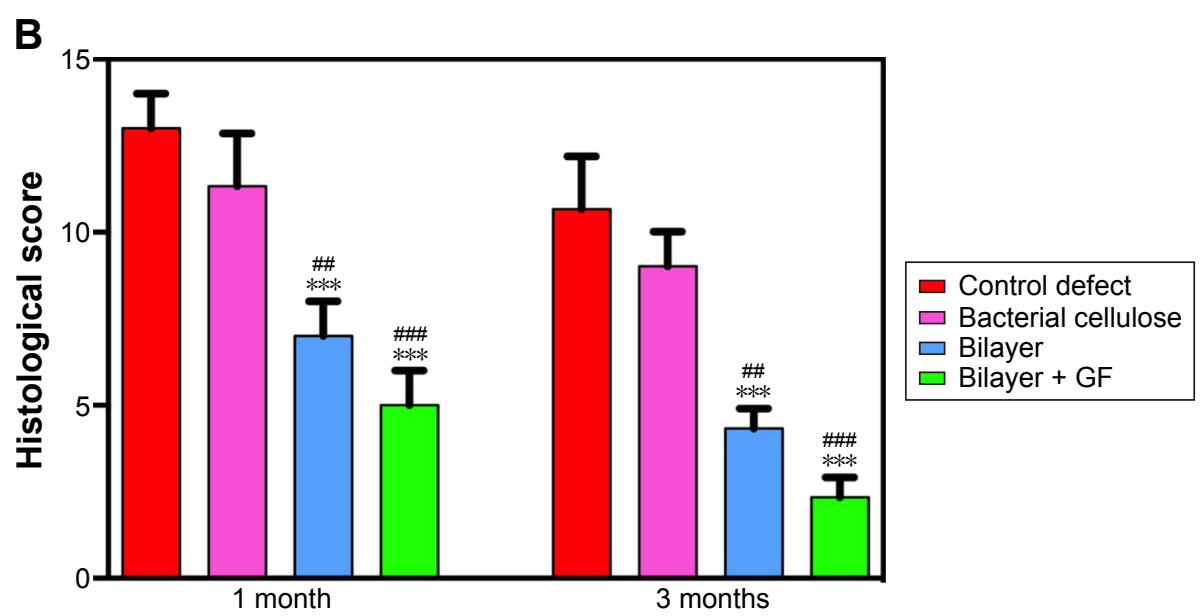

Figure 6 Histological observations.

Notes: (A) Safranin $O$ fast green staining of the repaired osteochondral tissue in different experimental groups at $\mathrm{I}$ and 3 months. Safranin $\mathrm{O}$ stains cartilage red and Fast green stains the underlying bone green. Cytoplasm stained gray and nuclei appear black. S-indicates scaffold; magnification $4 \times$. (B) Histological scoring in the different experimental groups at I and 3 months post scaffold implantation. Cell morphology was assessed on a scale of $0-4$, whereas matrix staining, surface regularity was assessed on a scale of $0-3$. Thickness of cartilage and integration of donor with host adjacent cartilage was assessed on a scale of 0-2. The defects were graded on a I4-point scale. Least scores indicate good repair of OCDs. Values expressed as mean $\pm S E M(n=3)$, ${ }^{* * *} P<0.00$ I versus control defect group. ${ }^{\#} P<0.0$ I, ${ }^{\# *} P<0.00$ I versus $B C$ scaffold.

Abbreviations: BC, bacterial cellulose; GF, growth factor; OCD, osteochondral defect; SEM, standard error of mean.

$282.52 \pm 18.99$ at 1 and 3 months, respectively, $P<0.001)$ compared to control defect group. In the case of bilayer $+\mathrm{GF}$ group, the BMD values were $233.51 \pm 7.46$ and $336.18 \pm 10.76$ at 1 and 3 months, respectively $(P<0.001$ vs control defect group and $\mathrm{BC}$ group and $P<0.01$ vs bilayer group). The results of $\mu \mathrm{CT}$ substantiate the results of the macroscopic and histological observations.

\section{Discussion}

$\mathrm{BC}$ is a naturally occurring nanofibrous structure which mimics the extracellular matrix. The rigid structure of $\mathrm{BC}$ allows sterilization under high pressure and heat without alteration in its native form. BC is equally amenable to chemical modifications. In comparison with large fibers, the ultra-fine nanofibers of $\mathrm{BC}$ provide improved mechanical strength and increased surface area for the attachment of cells. ${ }^{31}$
It is reported that $\mathrm{BC}$ has free hydroxyl groups that impart a weak positive surface charge. ${ }^{32}$ Considering all these properties, we aimed at the preparation of nanocomposite scaffolds (BC-HA and BC-GAG) mimicking the bone and the cartilage tissue to be repaired. For the preparation of BC-HA nanocomposites, the obvious choice was an optimal biomimetic mineralization synthesis approach employing SBF for the deposition of HA. ${ }^{24}$ For mimicking the cartilage, we chose chondroitin sulfate, a GAG of physiological significance. Chondroitin sulfate is a negatively charged molecule, and as anticipated, it was easily adsorbed on the surface of BC.

When the nanocomposites were analyzed with reference to their mechanical properties, data suggest that pristine $\mathrm{BC}$ was hard and less flexible. BC-HA was soft and elastic compared to both BC-GAG and BC. The modification with HA probably imparts the properties that are critical to the 
A
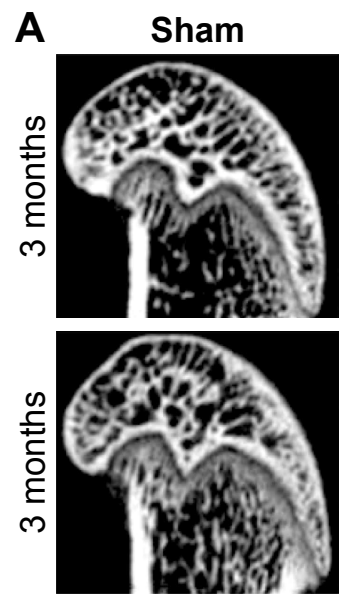

B

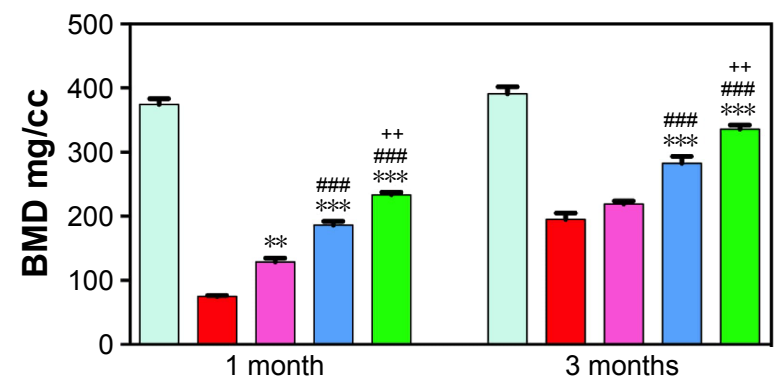

Control
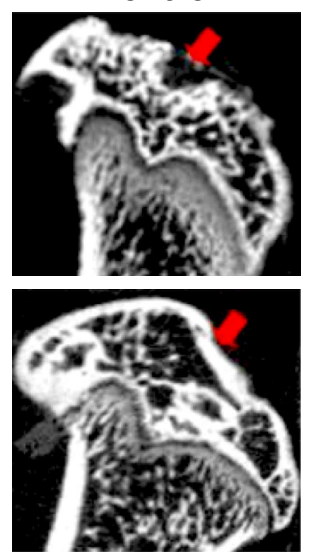

BC
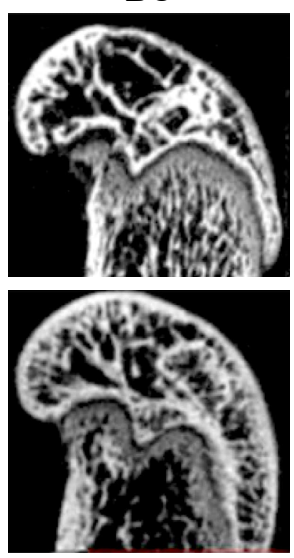

Bilayer
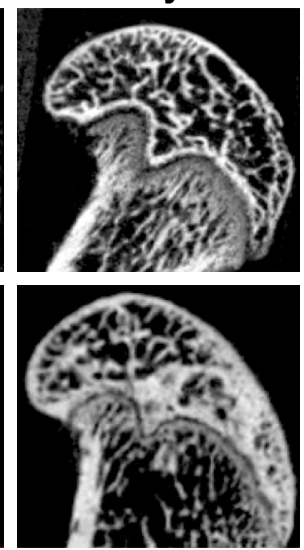

Bilayer + GF
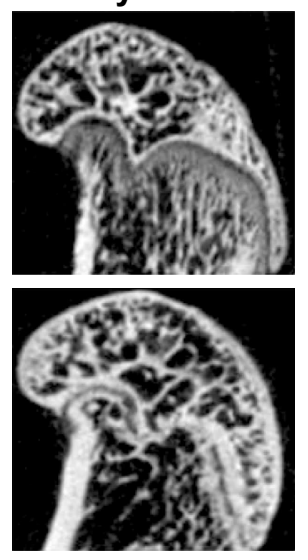

C

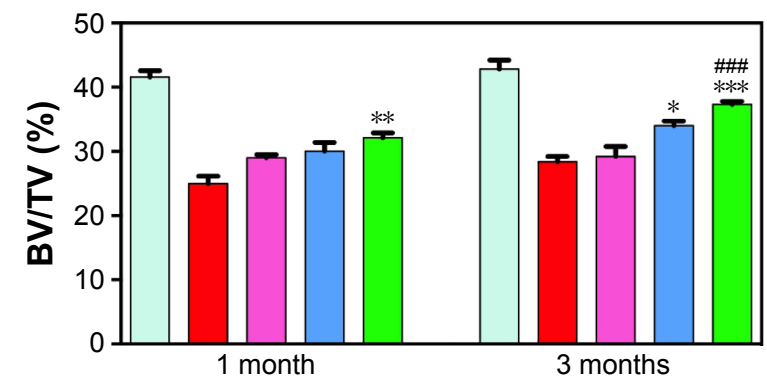

$\square$ Sham $\square$ Control defect $\square$ Bacterial cellulose $\square$ Bilayer $\square$ Bilayer + GF

Figure 7 Micro-CT evaluation for subchondral bone formation.

Notes: (A) Sagittally reconstructed micro-CT images of the representative excised knee specimen from each experimental group at I and 3 months post implantation (red arrows indicate the defect site). Reconstructed micro-CT images were used to analyze (B) the ratios of bone volume to tissue volume (BV/TV) and (C) bone mineral density (BMD) in each of the experimental group at I and 3 months post implantation. Values expressed as mean $\pm S E M(n=3)$, $* P<0.05$, $* * P<0.0 I$ and $* * * P<0.00 I$ versus control defect, ${ }^{\#} P<0.00$ I versus $B C$ scaffold group, ${ }^{++} P<0.0$ I versus bilayer group.

Abbreviations: BC, bacterial cellulose; CT, computer tomography; GF, growth factor; SEM, standard error of mean.

load-bearing application. Although the analysis was carried out using dry samples, we expect that the mechanical characteristics of BC-HA will improve further in the wet state. The results of FTIR analysis indicate that treatment of BC with PVP allowed interaction of $\mathrm{Ca}^{2+}$ ions through dynamic ion-polar interaction due to the presence of $\mathrm{C}-\mathrm{N}$ and $\mathrm{C}=\mathrm{O}$. Then the incorporated $\mathrm{Ca}^{2+}$ ions could facilitate the interaction of $\mathrm{PO}_{4}{ }^{3-}$ and $\mathrm{CO}_{3}{ }^{2-}$ ions in $1.5 \times \mathrm{SBF}$ solution with $\mathrm{BC}$ via electrostatic interaction leading to the deposition of HA crystals. The results of FTIR data are in accord with previous studies. ${ }^{24,33}$ FTIR data of BC-GAG composites also indicate that apart from the characteristic peaks for chondroitin sulfate, there are no new peaks. FTIR suggests no bond formation between $\mathrm{BC}$ and chondroitin sulfate and that the interaction was primarily due to the phenomenon of adsorption.

Morphological analysis (scanning electron microscopy) of BC-HA produced was in agreement with the earlier reports. ${ }^{24}$ The sharp peaks in the XRD pattern of native BC indicate that the cellulose produced by $K$. hansenii MCM
B-967 is highly crystalline..$^{13}$ In the present study of BC-HA, additional peaks observed at $10.6^{\circ}, 27.2^{\circ}, 31.8^{\circ}, 40.5^{\circ}, 45.6^{\circ}$, and $56.6^{\circ}$ could be assigned to HA crystals formed due to the activation of $\mathrm{BC}$ by $\mathrm{Ca}^{2+}$, followed by mineralization in $1.5 \times$ $\mathrm{SBF}$. The decrease in the intensity of characteristic peaks of cellulose in the nanocomposite indicates that HA (ICDDPDF file number 9-432) is the dominating component of the composite. ${ }^{24,33}$ The XRD pattern of BC-GAG composite was comparable to that of native $\mathrm{BC}$, probably due to the non-crystalline nature of GAG.

In vitro studies indicated that in comparison with $\mathrm{BC}$, the rough surface of BC-HA nanocomposite favored attachment of SaOS-2, which is in agreement with an earlier report. ${ }^{34} \mathrm{AP}$ is a membrane-bound enzyme which is an early marker of osteoblastic differentiation. It hydrolyzes pyrophosphate to facilitate mineralization, precipitation, and growth. ${ }^{35}$ In this study, the presence of higher AP-positive cells correlates well with the data on cell differentiation. Calcified BC is reported to resist vascular invasion from subchondral tissue and prevent osseous growth, ${ }^{36}$ making it a desirable property 
in the current study. Our study shows that BC-GAG scaffolds supported proliferation of primary articular chondrocytes and expression of chondrocyte markers was better compared to native BC. This could be because GAGs helps in adhesion, migration, proliferation, differentiation of cells and are practically non-immunogenic. ${ }^{37}$

According to our observations, modification of BC with GAG and HA have positively influenced cell proliferation and growth of hATMSC. Observations on cell proliferation indicate the usefulness of a 3D surface (the scaffold) that provides a higher surface area over a 2D surface (tissue culture plate). Expression of differentiation markers, for example, AP, mineralization, and sGAG production is indeed indicative of cell differentiation into respective lineages. Furthermore, hATMSC were able to differentiate into osteoblasts and chondrocytes onto BC-HA and BC-GAG scaffolds, respectively. These results of differentiation of hATMSC into osteoblasts are in agreement with the findings of previous study, which demonstrated that the BC-HA nanocomposites enhanced osteoblastic differentiation of MSC in the absence of osteoinductive reagents. ${ }^{19}$ Furthermore, production of sGAG after differentiation of hATMSC into chondrocytes was significantly higher in BC-GAG nanocomposites compared to native BC. Thus, BC-HA and BC-GAG scaffolds provide an adequate $3 \mathrm{D}$ support for cell proliferation and enhance the functional activity of hATMSC. The results with SaOS-2, hAC, and hATMSC unequivocally establish the in vitro biocompatibility of the nanocomposite scaffolds. To the best of our knowledge, we prove the osteoinductive and chondroinductive capacity of the modified BC scaffolds for the first time.

It is well known that angiogenesis/neovascularization associated with implanted biomaterials/scaffolds depends on bioactive nature, the porosity of the scaffold, and the metabolic activity of the infiltrating host tissue. ${ }^{38}$ The present study on the in vivo biocompatibility of BC-based scaffolds after subcutaneous implantation indicate that $\mathrm{BC}, \mathrm{BC}-\mathrm{HA}$, and $\mathrm{BC}-\mathrm{GAG}$ are bioactive porous scaffolds that facilitate complete and uniform infiltration of host tissue, ultimately resulting in a well-spread blood vascular network at the implantation site. The absence of inflammation or immunological reactions proved the in vivo biocompatibility of native $\mathrm{BC}$ scaffolds which corroborate the earlier findings. ${ }^{39}$ The whitish appearance of BC-HA scaffolds could be due to the increase in the local saturation of biologic fluid causing precipitation of carbonated apatite onto scaffolds, analogous to an earlier report. ${ }^{40}$

Most of the current approaches for repairing OCD include the addition of cell populations such as chondrocytes ${ }^{9,41}$ or
$\mathrm{MSCs}^{42,43}$ in a variety of carrier matrices that are delivered to the defect site. We adopted acellular scaffolds considering the potential risks associated with cell-based strategies. Use of acellular strategies would circumvent the risks of disease transmission, immune rejection, and possible tumorigenesis, thus proving to be quite advantageous for clinical applications. Use of acellular scaffolds containing growth factors in the repair of OCD is considered to be a more realistic approach, with possibly easy implementation in the clinics. This strategic approach could lead to the functionalization of scaffolds. The osteogenic potential of BMP-2 (which helps in repairing subchondral bone in vivo) is well documented. ${ }^{44}$ TGF- $\beta 3$ also plays a significant role in the regulatory network of growth factors that maintains articular cartilage and is an essential element for inducing chondrogenesis in marrow-derived MSCs. ${ }^{45}$ Therefore, in the present study, the BC-HA and BC-GAG scaffolds were modified with BMP-2 and TGF- $\beta 3$, respectively, and implanted without loading cells.

Since we used acellular scaffolds in this study, we presumed migration of cells erupted from the underlying bone marrow in BC-based scaffolds. Notably, in the bilayer groups, progressive regeneration of cartilage tissue was observed over time, as evidenced by enhanced cartilage ECM deposition of proteoglycans. In the deeper layer, the regenerated subchondral bone was found in $\mu \mathrm{CT}$. $\mu \mathrm{CT}$ scanning is a relatively new approach in the bone-engineering field where the technique can be utilized to calculate the BV based on real 3D spatial distribution. ${ }^{46}$ In the present study, this technique complemented well with the histological assessment. The subchondral bone formation may have resulted from osteoconductive property of nanocomposite $\mathrm{BC}-\mathrm{HA}$ activated with BMP-2. This is in conjunction with previous reports $s^{5,47,48}$ where subchondral bone formation is reported to enhance regeneration of the articular cartilage. In the current in vivo study, the size of the modified BC scaffold was significantly reduced at 3 months, indicating biodegradative resorption and integration in the surrounding tissue. This observation matches with the degradation potential of BC immersed in PBS. ${ }^{49,50}$ In other studies, cell-free Ar-HA scaffolds ${ }^{51}$ were implanted in a goat model; and the results indicated that cell-free scaffold can retard osteoarthritic changes in the cartilage surrounding the focal defect. The results obtained in our study are similar to the reports on the use of cell-free multilayered collagen-based scaffolds for regeneration of functional osteochondral tissue in carpine joints. ${ }^{52}$ Our study proves that BC-based acellular scaffolds cause recruitment of host cells, circumventing the need of pre-culture of cells. The infiltrating cells are capable of differentiation into bone-like 
and cartilage-like cells primarily because of the scaffold architecture and the growth factors provided.

\section{Conclusion}

In this study, we described the development of new BC-based nanocomposite bilayer scaffolds consisting of BC-HA and BC-GAG that could support attachment and in vitro proliferation of osteoblasts and hACs, respectively. Furthermore, these scaffolds allowed tissue ingrowth and induced no inflammation or immunological reactions after subcutaneous implantation in rats. Since we used acellular scaffolds in this study, we presumed migration of cells erupted from the underlying bone marrow in BC-based scaffolds. The significant findings of in vivo studies revealed that acellular BC-based bilayer scaffolds simultaneously accelerated the regeneration of articular cartilage and subchondral bone in a rat model of OCD. The scaffolds provide functional capability which is a very important aspect in tissue engineering. To the best of our knowledge, the present study, for the first time, highlights that a single biopolymer, for example, $\mathrm{BC}$ could be modified to mimic two structurally different tissues, and $\mathrm{BC}$ exhibited highly desirable biodegradative resorption capability. The present study constitutes a preclinical evaluation of BC-based acellular scaffolds concerning the repair of OCD. The use of acellular scaffolds might allow simplification of the osteochondral treatment algorithm. The data presented warrants further extensive and long-term evaluation of BC nanocomposite scaffolds in other animals as well as humans for the eventual translation into clinical practice.

\section{Acknowledgments}

JVK is thankful to CSIR, Government of India, New Delhi, for providing research fellowship. The authors are thankful to Mr Sanjay Vaidya, Dr Chintan Bhatt, and Pratyank Rastogi for carrying out nano-indentation analysis at Hysitron Nanotechnology India, Trivandrum. They also acknowledge the financial support from DST, Government of India, New Delhi, for carrying out the research.

\section{Disclosure}

The authors report no conflicts of interest in this work.

\section{References}

1. Davitt JS, Rothberg DL. Treatment of talar osteochondral lesions in athletes: approaches for treatment. Oper Tech Sports Med. 2010; 18:53-59.

2. Pánics G, Hangody LR, Baló E, Vásárhelyi G, Gál T, Hangody L. Osteochondral autograft and mosaicplasty in the football (soccer) athlete. Cartilage. 2012;3:25S-30S.
3. Gotterbarm T, Richter W, Jung M, et al. An in vivo study of a growthfactor enhanced, cell free, two-layered collagen-tricalcium phosphate in deep osteochondral defects. Biomaterials. 2006;27:3387-3395.

4. Nukavarapu SP, Dorcemus DL. Osteochondral tissue engineering: current strategies and challenges. Biotechnol Adv. 2013;31:706-721.

5. Yan LP, Silva-Correia J, Oliveira MB, et al. Bilayered silk/silknanocap scaffolds for osteochondral tissue engineering: in vitro and in vivo assessment of biological performance. Acta Biomater. 2015;12: 227-241.

6. Prockop DJ. Repair of tissues by adult stem/progenitor cells (mscs): controversies, myths, and changing paradigms. Mol Ther. 2009;17: 939-946.

7. Re'em T, Witte F, Willbold E, Ruvinov E, Cohen S. Simultaneous regeneration of articular cartilage and subchondral bone induced by spatially presented TGF-beta and BMP-4 in a bilayer affinity binding system. Acta Biomater. 2012;8:3283-3293.

8. Shah RN, Shah NA, Del Rosario Lim MM. Supramolecular design of self-assembling nanofibers for cartilage regeneration. Proc Natl Acad Sci US A. 2010;107:3293-3298.

9. Reyes R, Pec MK, Sánchez E, del Rosario C, Delgado A, Évora C. Stem cells versus chondrocytes versus bone morphogenetic protein-2, solely or in combination. Eur Cells Mater. 2012;25:351-365.

10. Deans TL, Elisseeff JH. Stem cells in musculoskeletal engineered tissue. Curr Opin Biotechnol. 2009;20:537-544.

11. Dhandayuthapani B, Yoshida Y, Maekawa T, et al. Polymeric scaffolds in tissue engineering application: a review. Intl J Polym Sci. 2011; Article ID 290602.

12. Shao XX, Hutmacher DW, Ho ST, Goh JC, Lee EH. Evaluation of a hybrid scaffold/cell construct in repair of high-load-bearing osteochondral defects in rabbits. Biomaterials. 2006;27:1071-1080.

13. Kumbhar JV, Rajwade JM, Paknikar KM. Fruit peels support higher yield and superior quality bacterial cellulose production. Appl Microbiol Biotechnol. 2015;99:6677-6691.

14. Rajwade JM, Paknikar KM, Kumbhar JV. Applications of bacterial cellulose and its composites in biomedicine. Appl Microbiol Biotechnol. 2015;99:2491-2511.

15. Svensson A, Nicklasson E, Harrah T, et al. Bacterial cellulose as a potential scaffold for tissue engineering of cartilage. Biomaterials. 2005;26:419-431.

16. Yadav V, Sun L, Panilaitis B, Kaplan DL. In vitro chondrogenesis with lysozyme susceptible bacterial cellulose as a scaffold. J Tissue Eng Regen Med. 2015;9:E276-E288.

17. Yin N, Stilwell MD, Santos TMA, Wang H, Weibel DB. Agarose particle-templated porous bacterial cellulose and its application in cartilage growth in vitro. Acta Biomater. 2015;12:129-138.

18. Ávila HM, Feldmann EM, Pleumeekers MM, et al. Novel bilayer bacterial nanocellulose scaffold supports neocartilage formation in vitro and in vivo. Biomaterials. 2015;44:122-133.

19. Fang B, Wan Y, Tang T, Gao C, Dai KR. Proliferation and osteoblastic differentiation of human bone marrow stromal cells on hydroxyapatite/ bacterial cellulose nanocomposite scaffolds. Tissue Eng Part A. 2009;15: 1091-1099.

20. Grande CJ, Torres FG, Gomez CM, Bañó MC. Nanocomposites of bacterial cellulose/hydroxyapatite for biomedical applications. Acta Biomater. 2009;5:1605-1615.

21. Zimmermann KA, LeBlanc JM, Sheets KT, Fox RW, Gatenholm P. Biomimetic design of a bacterial cellulose/hydroxyapatite nanocomposite for bone healing applications. Mater Sci Eng C. 2011;31:43-49.

22. Tazi N, Zhang Z, Messaddeq Y, et al. Hydroxyapatite bioactivated bacterial cellulose promotes osteoblast growth and the formation of bone nodules. AMB Express. 2012;2:61.

23. Giannoni P, Lazzarini E, Ceseracciu L, Barone AC, Quarto R, Scaglione $\mathrm{S}$. Design and characterization of a tissue-engineered bilayer scaffold for osteochondral tissue repair. J Tissue Eng Regen Med. 2015; 9:1182-1192.

24. Yin N, Chen S, Ouyang Y, Tang L, Yang J, Wang H. Biomimetic mineralization synthesis of hydroxyapatite bacterial cellulose nanocomposites. Prog Nat Sci. 2011;21:472-477. 
25. Barbosa I, Caruelle J. Improved and simple micro assay for sulfated glycosaminoglycans quantification in biological extracts and its use in skin and muscle tissue studies. Glycobiology. 2003;13:647-653.

26. Gregory CA, Gunn WG, Peister A, Prockop DJ. An alizarin red-based assay of mineralization by adherent cells in culture: comparison with cetylpyridinium chloride extraction. Anal Biochem. 2004;329: 77-84.

27. Stanford CM, Jacobson PA, Eanes ED, Lembke LA, Midura RJ. Rapidly forming apatitic mineral in an osteoblastic cell line (UMR 10601 BSP). J Biol Chem. 1995;270:9420-9428.

28. Saha S, Kundu B, Kirkham J, Wood D, Kundu SC, Yang XB. Osteochondral tissue engineering in vivo: a comparative study using layered silk fibroin scaffolds from mulberry and nonmulberry silkworms. PLoS One. 2013;8:e80004.

29. Fortier LA, Mohammed HO, Lust G, Nixon AJ. Insulin-like growth factor-I enhances cell-based repair of articular cartilage. J Bone Joint Surg Br. 2002;84:276-288.

30. Wakitani VMGS, Goto T, Pineda S, et al. Mesenchymal cell-based repair of large full thickness defects of articular cartilage. J Bone Joint Surg Am. 1994;76:441-443.

31. Li WJ, Tuli R, Huang X, Laquerriere P, Tuan RA. Multilineage differentiation of human mesenchymal stem cells in a three-dimensional nanofibrous scaffold. Biomaterials. 2005;26:5158-5166.

32. Luan J, Wu J, Zheng Y, et al. Impregnation of silver sulfadiazine into bacterial cellulose for antimicrobial and biocompatible wound dressing. Biomed Mater. 2012;7:065006.

33. Hutchens SA, Benson RS, Evans BR, O’Neill HM, Rawn CJ. Biomimetic synthesis of calcium-deficient hydroxyapatite in a natural hydrogel. Biomaterials. 2006;27:4661-4670.

34. Curtis A, Wilkinson C. Topographical control of cells. Biomaterials. 1997; 18:1573-1583.

35. Saska S, Teixeira LN, Tambasco de Oliveira P, et al. Bacterial cellulosecollagen nanocomposite for bone tissue engineering. J Mater Chem. 2012;22:22102.

36. Da H, Jia SJ, Meng GL, et al. The impact of compact layer in biphasic scaffold on osteochondral tissue engineering. PLoS One. 2013; 8:e54838.

37. Pieper JS, Oosterhof A, Dijkstra PJ, Veerkamp JH, van Kuppevelt TH. Preparation and characterization of porous crosslinked collagenous matrices containing bioavailable chondroitin sulphate. Biomaterials. 1999;20:847-858.

38. Burugapalli K, Pandit A. Characterization of tissue response and in vivo degradation of cholecyst-derived extracellular matrix. Biomacromolecules. 2007;8(11):3439-3451.
39. Helenius G, Bäckdahl H, Bodin A, Nannmark U, Gatenholm P, Risberg B. In vivo biocompatibility of bacterial cellulose. J Biomed Mater Res A. 2006;76:431-438

40. Fricain JC, Schlaubitz S, Le C, et al. A nano-hydroxyapatite-pullulan/ dextran polysaccharide composite macroporous material for bone tissue engineering. Biomaterials. 2013;34:2947-2959.

41. De Franceschi L, Grigolo B, Roseti L, et al. Transplantation of chondrocytes seeded on collagen-based scaffold in cartilage defects in rabbits. J Biomed Mater Res A. 2005;75:612-622.

42. Giannoni S, Buda R, Vannini F, Cavallo M, Grigolo B. One-step bone marrow-derived cell transplantation in talar osteochondral lesions. Clin Orthop Relat Res. 2009;467:3307-3320.

43. Dahlin RL, Kinard LA, Lam J, et al. Articular chondrocytes and mesenchymal stem cells seeded on biodegradable scaffolds for the repair of cartilage in a rat osteochondral defect model. Biomaterials. 2014; 35:7460-7469.

44. Morales YL, Abarrategi A, Ramos V, et al. In vivo comparison of the effects of rhbmp-2 and rhbmp-4 in osteochondral tissue regeneration. Eur Cell Mater. 2010;20:367-378.

45. Solchaga LA, Penick KJ, Welter JF. Chondrogenic differentiation of bone marrow-derived mesenchymal stem cells: tips and tricks. Methods Mol Biol. 2011;698:253-278.

46. Young S, Kretlow JD, Nguyen C, et al. Microcomputed tomography characterization of neovascularization in bone tissue engineering applications. Tissue Eng B Rev. 2008;14:295-306.

47. Maehara H, Sotome S, Yoshii T, et al. Repair of large osteochondral defects in rabbits using porous hydroxyapatite/collagen (hap/col) and fibroblast growth factor-2 (fgf-2). J Orthop Res. 2010;28:677-686.

48. Hrabchak C, Rouleau J, Moss I, et al. Assessment of biocompatibility and initial evaluation of genipin cross-linked elastin-like polypeptides in the treatment of an osteochondral knee defect in rabbits. Acta Biomater. 2010;6:2108-2115.

49. Chen YM. In vitro cytotoxicity of bacterial cellulose scaffolds used for tissue-engineered bone. J Bioact Compat Polym. 2009;24:137-145.

50. Chen YM, Xi TF, Zheng YF, Zhou L, Wan YZ. In vitro structural changes of nano-bacterial cellulose immersed in phosphate buffer solution. J Biomim Biomater Tissue Eng. 2011;10:55-66.

51. Kon E, Filardo G, Shani J, et al. Osteochondral regeneration with a novel aragonite-hyaluronate biphasic scaffold: up to 12-month follow-up study in a goat model. J Ortho Surg Res. 2015;10:81.

52. Levingstone TJ, Ramesh A, Brady RT, Brama PAJ, Kearney C. Cellfree multi-layered collagen-based scaffolds demonstrate layer specific regeneration of functional osteochondral tissue in caprine joints. Biomaterials. 2016;87:69-81. 


\section{Supplementary materials}
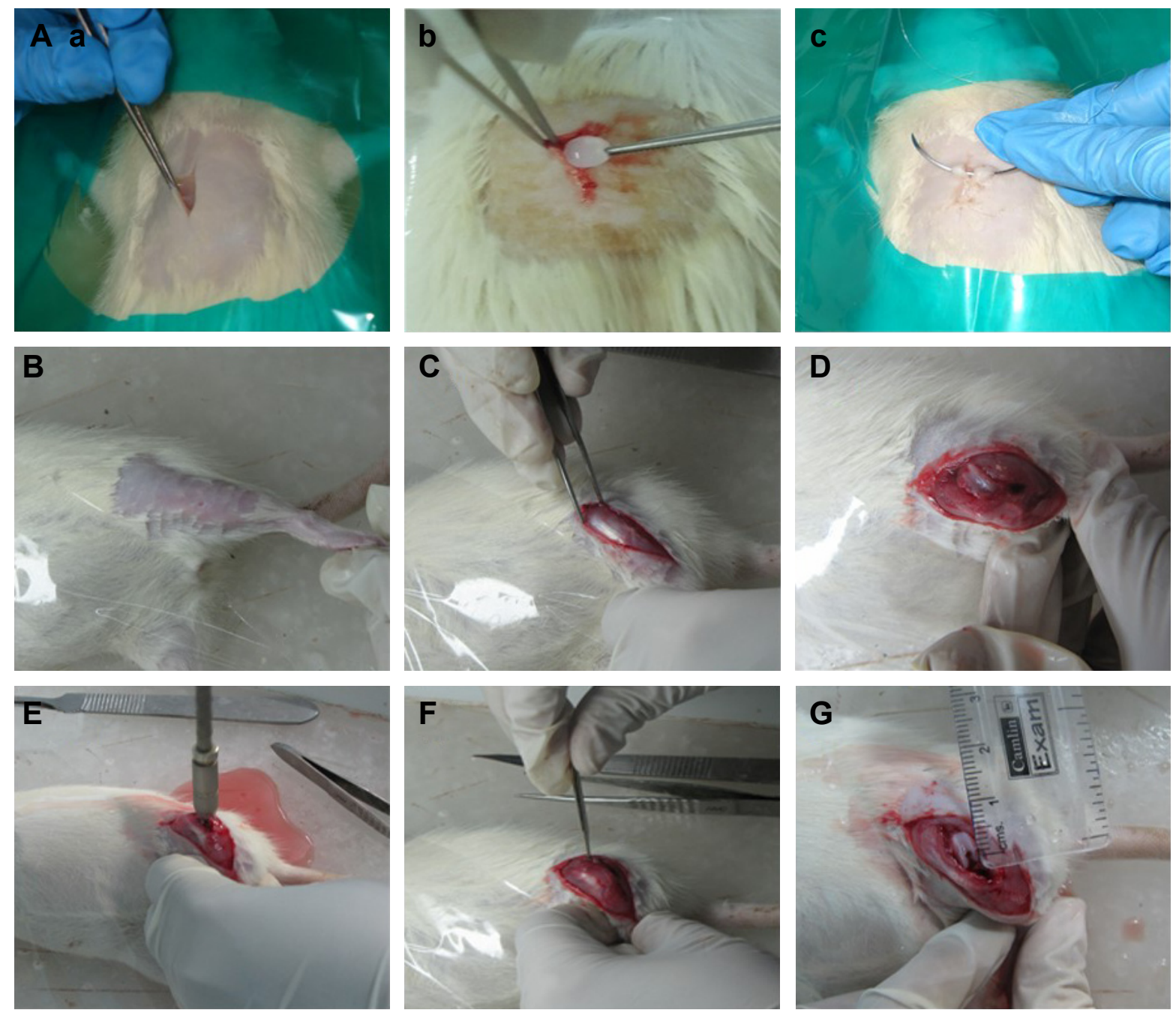

Figure SI In vivo surgical procedures.

Notes: (A a-c) Surgical procedure of subcutaneous implantation of scaffolds; (B-G) surgical procedure for the creation of osteochondral defects. (B) Shaving to clean the surgical area. (C and D) Skin incision and exposure of patellar groove. (E) Creation of defect using a hand drill. (F) Creating a defect of $\mathrm{I} \mathrm{mm}$ diameter and $3 \mathrm{~mm}$ in depth using a dental burr $(\mathbf{G})$ osteochondral defect. 
Table SI Scoring system used in the study

\begin{tabular}{|c|c|c|}
\hline Analysis & Score & Qualifications \\
\hline \multicolumn{3}{|l|}{ Articular cartilage repair scoring system } \\
\hline \multirow[t]{4}{*}{ Surface texture of repair tissue } & 0 & Normal, smooth, hyaline \\
\hline & 1 & $>75 \%$ normal \\
\hline & 2 & $50 \%-75 \%$ normal \\
\hline & 3 & $<50 \%$ normal \\
\hline \multirow[t]{4}{*}{ Percent area of defect filled } & 0 & $100 \%$ \\
\hline & 1 & $>75 \%$ normal \\
\hline & 2 & $50 \%-75 \%$ normal \\
\hline & 3 & $<50 \%$ normal \\
\hline \multirow[t]{4}{*}{ Graft-recipient tissue integration } & 0 & $100 \%$ of perimeter \\
\hline & I & $>75 \%$ normal \\
\hline & 2 & $50 \%-75 \%$ normal \\
\hline & 3 & $<50 \%$ normal \\
\hline Total maximum & 9 & \\
\hline \multicolumn{3}{|l|}{ Articular cartilage repair scoring system } \\
\hline \multirow[t]{5}{*}{ Cell morphology } & 0 & Hyaline cartilage \\
\hline & 1 & Mostly hyaline cartilage \\
\hline & 2 & Mostly fibrocartilage \\
\hline & 3 & Mostly non-cartilage \\
\hline & 4 & Non-cartilage only \\
\hline \multirow[t]{4}{*}{ Matrix staining (metachomasia) } & 0 & Normal compared with host adjacent cartilage \\
\hline & 1 & Slightly reduced \\
\hline & 2 & Markedly reduced \\
\hline & 3 & No metacromatic stain \\
\hline \multirow[t]{4}{*}{ Surface regularity } & 0 & Smooth $(>3 / 4)$ \\
\hline & 1 & Moderate $(>1 / 2$ to $3 / 4)$ \\
\hline & 2 & Irregular ( $1 / 4$ to $\mathrm{I} / 2)$ \\
\hline & 3 & Severely irregular $(<\mathrm{I} / 4)$ \\
\hline \multirow[t]{3}{*}{ Thickness of the cartilage } & 0 & $>2 / 3$ \\
\hline & 1 & $1 / 3$ to $2 / 3$ \\
\hline & 2 & $<1 / 3$ \\
\hline \multirow[t]{3}{*}{ Integration of donor with host adjacent cartilage } & 0 & Both edges integrated \\
\hline & 1 & One edge integrated \\
\hline & 2 & Neither edge integrated \\
\hline Total maximum & 14 & \\
\hline
\end{tabular}
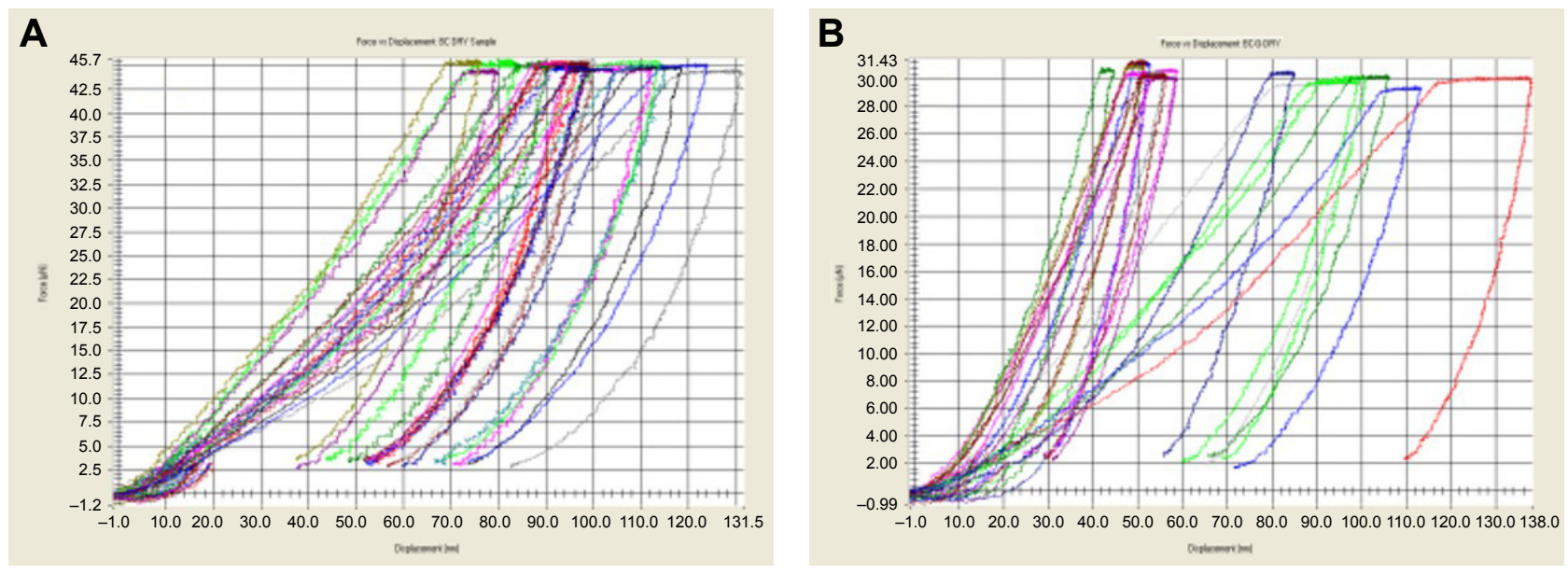

Figure S2 (Continued) 


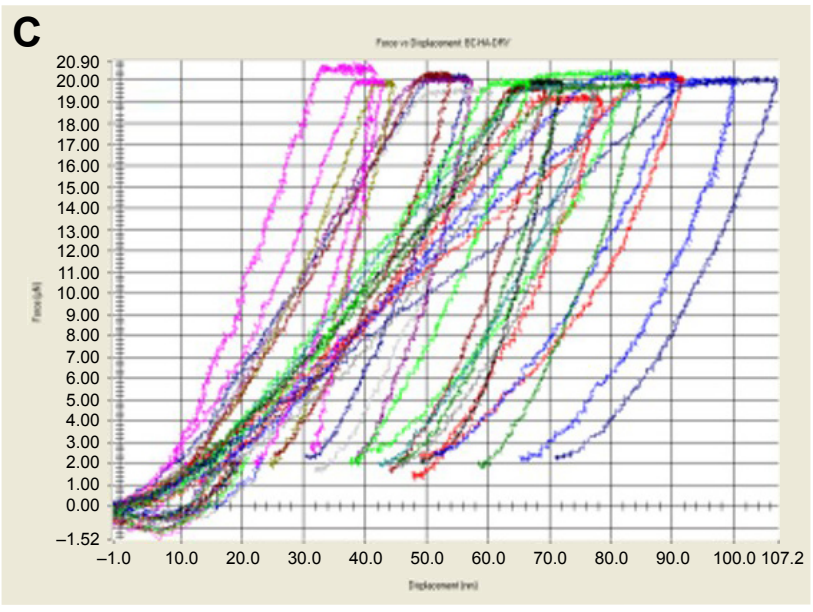

Figure S2 Load displacement curves generated from nanoindentation analysis of (A) BC, (B) BC-GAG, and (C) BC-HA samples. Abbreviations: $B C$, bacterial cellulose; $B C-G A G, B C$-glycosaminoglycans; BC-HA, BC-hydroxyapatite.

A

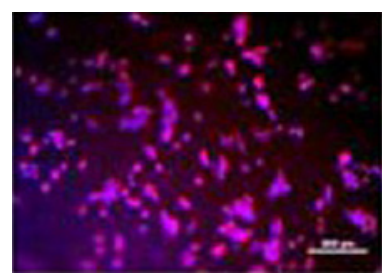

DAPI rhodamine staining

C

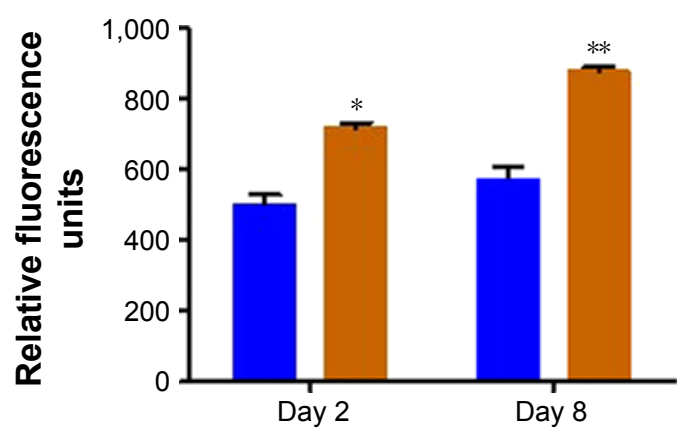

B
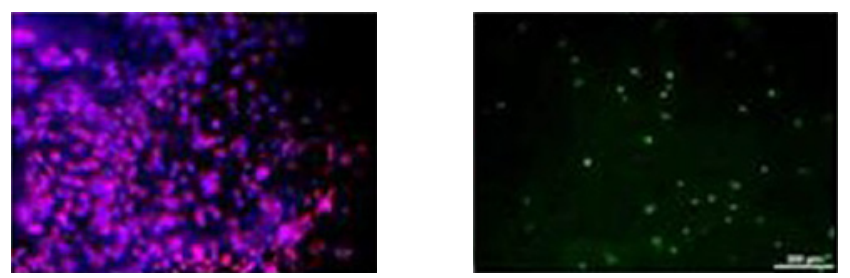

AP staining

D

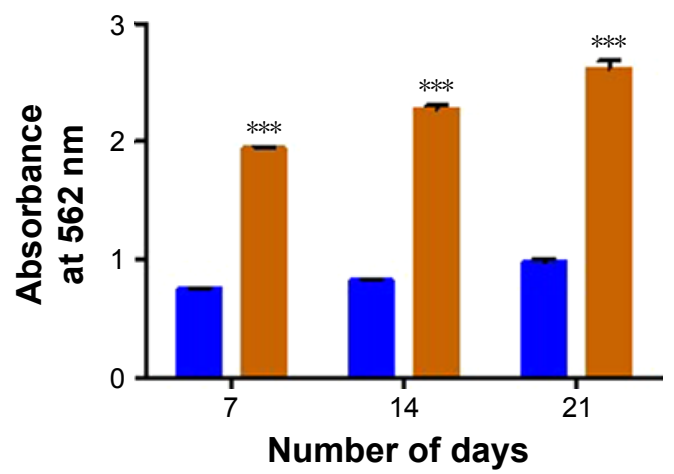

$\mathrm{BC} \square \mathrm{BC}-\mathrm{HA}$

E

BC

BC-GAG
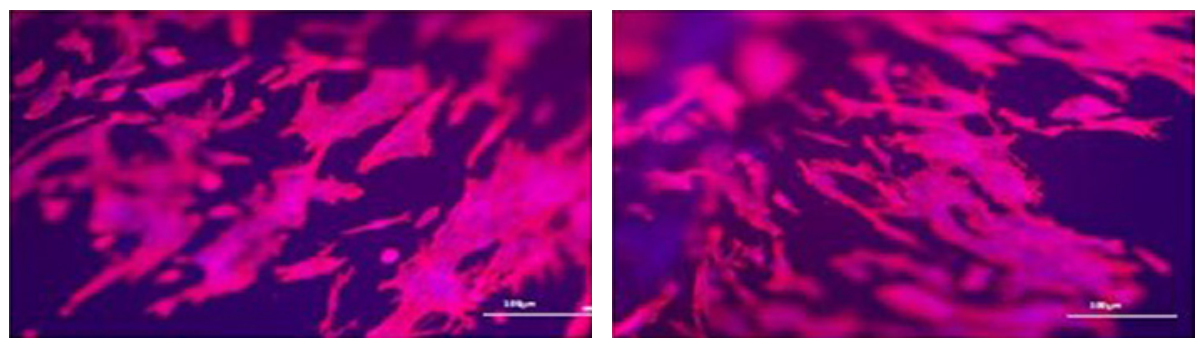

DAPI rhodamine staining

Figure S3 (Continued) 
$\mathbf{F}$

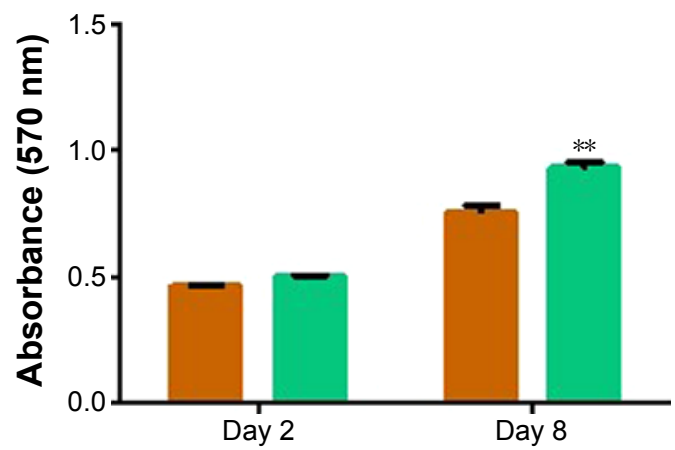

G

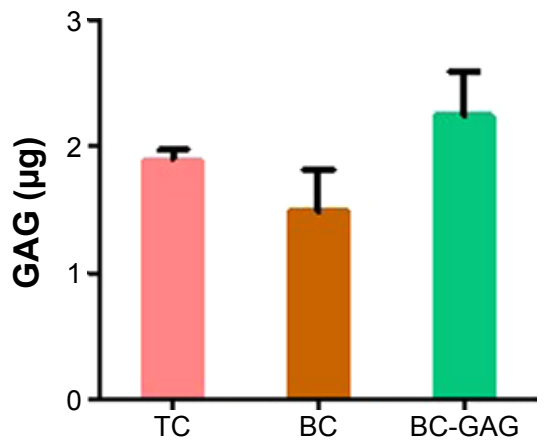

BC $\square$ BC-GAG

Figure $\mathbf{S} 3$ In vitro studies using osteoblasts (SaOS-2) and chondrocytes (hAC).

Notes: (A) Growth of SaOS-2 on BC and BC-HA scaffolds showing DAPI rhodamine staining. (B) AP staining of BC and BC-HA scaffolds. (C) Proliferation of SaOS-2 cells on $B C$ and $B C-H A$ scaffolds. ${ }^{*} P<0.05$ versus $B C$ control, ${ }^{*} * P<0.0$ I versus $B C$ control. (D) Mineralization by SaOS- 2 cells on $B C$ and $B C-H A$ scaffolds. Mean $\pm S E M$ ( $n=3$ ), $* * * P<0.00 \mathrm{I}$ versus $B C$ control. (E) DAPI rhodamine staining of $B C$ and $B C-G A G$ scaffolds seeded with $h A C$. (F) Proliferation of hAC on $B C$ and $B C-G A G$ scaffolds, $* * P<0.01$ versus. BC control. (G) Estimation of sGAG deposited on BC and BC-GAG scaffolds. Mean \pm SEM ( $n=3)$. Scale bars represent $50 \mu \mathrm{m}(\mathbf{A}$ and $\mathbf{B})$ and I00 $\mu \mathrm{m}$ (E).

Abbreviations: BC, bacterial cellulose; BC-HA, BC-hydroxyapatite; GAG, glycosaminoglycans; hAC, human articular chondrocyte; DAPI, 4',6-diamidino-2-phenylindole, dihydrochloride; sGAG, sulfated glycosaminoglycans; AP, alkaline phosphatase; TC, tissue culture plate; SEM, standard error of mean.

Table S2 Blood hematology parameters and cytokine IL- I $\alpha$ and TNF- $\alpha$ levels in sham-operated and scaffold implanted rats (after I5 and 45 days post implantation)

\begin{tabular}{|c|c|c|c|c|c|c|c|c|}
\hline \multirow{2}{*}{$\begin{array}{l}\text { Groups } \\
\text { parameters }\end{array}$} & \multicolumn{2}{|l|}{ Sham } & \multicolumn{2}{|l|}{ BC } & \multicolumn{2}{|l|}{ BC-HA } & \multicolumn{2}{|l|}{ BC-GAG } \\
\hline & 15 & 45 & 15 & 45 & 15 & 45 & 15 & 45 \\
\hline WBC ( $\left(10^{9} / \mathrm{L}\right)$ & $9.43 \pm 0.37$ & $9.1 \pm 0.18$ & $10.33 \pm 0.40$ & $9.1 \pm 0.42$ & $8.33 \pm 0.32$ & $8.7 \pm 0.32$ & $9.95 \pm 0.60$ & $8.6 \pm 0.33$ \\
\hline $\operatorname{RBC}\left(10^{12} / \mathrm{L}\right)$ & $6.5 \pm 0.17$ & $7.3 \pm 0.15$ & $6.8 \pm 0.29$ & $7.2 \pm 0.15$ & $6.8 \pm 0.10$ & $7.6 \pm 0.07$ & $6.6 \pm 0.13$ & $7.8 \pm 0.11$ \\
\hline HGB (g/dl) & $13.5 \pm 0.33$ & $14.6 \pm 0.28$ & $14.2 \pm 0.85$ & $14.5 \pm 0.26$ & $13.9 \pm 0.23$ & $14.9 \pm 0.15$ & $13.5 \pm 0.28$ & $15 \pm 0.29$ \\
\hline HCT (\%) & $38.5 \pm 0.72$ & $41.9 \pm 0.52$ & $39.7 \pm 2.26$ & $40.7 \pm 0.83$ & $39.2 \pm 0.44$ & $42.5 \pm 0.33$ & $38.4 \pm 0.58$ & $42.6 \pm 0.73$ \\
\hline MCV (fL) & $58.4 \pm 0.53$ & $57.9 \pm 0.77$ & $57.4 \pm 0.4 \mathrm{I}$ & $61.7 \pm 4.74$ & $57.1 \pm 0.70$ & $56.2 \pm 0.39$ & $57.9 \pm 0.59$ & $55.5 \pm 0.37$ \\
\hline $\mathrm{MCH}(\mathrm{pg})$ & $20.7 \pm 0.13$ & $20.2 \pm 0.16$ & $20.2 \pm 0.27$ & $22.0 \pm 1.86$ & $20.2 \pm 0.15$ & $19.6 \pm 0.13$ & $20.4 \pm 0.21$ & $19.2 \pm 0.17$ \\
\hline $\mathrm{MCHC}(g / d \mathrm{l})$ & $34.9 \pm 0.26$ & $35.2 \pm 0.24$ & $33.9 \pm 1.50$ & $35.6 \pm 0.32$ & $34.9 \pm 0.45$ & $35.0 \pm 0.12$ & $35.2 \pm 0.32$ & $34.9 \pm 0.36$ \\
\hline IL-I $\alpha(p g / m L)$ & $|5.0| \pm \mid .20$ & $14.62 \pm 0.39$ & $1 \mathrm{I} .67 \pm 0.48$ & $13.58 \pm 2.10$ & $11.26 \pm 0.76$ & $12.62 \pm 1.27$ & || $.52 \pm 0.7 \mid$ & $11.50 \pm 1.58$ \\
\hline TNF- $\alpha$ (pg/mL) & $14.45 \pm 3.34$ & $13.59 \pm 3.90$ & $13.55 \pm 0.09$ & $12.06 \pm 0.68$ & $16.22 \pm 4.59$ & $13.39 \pm 2.29$ & $20.55 \pm 6.63$ & $17.96 \pm 7.86$ \\
\hline
\end{tabular}

Abbreviations: BC, bacterial cellulose; BC-GAG, BC-glycosaminoglycans; BC-HA, Bc-hydroxyapatite; IL-I $\alpha$, interleukin-I $\alpha$; TNF- $\alpha$, tumor necrosis factor- $\alpha$; HGB, hemoglobin; $\mathrm{HCT}$, hematocrit; $\mathrm{MCV}$, mean corpuscular volume; $\mathrm{MCH}$, mean corpuscular hemoglobin; $\mathrm{MCHC}$, mean corpuscular hemoglobin concentration. 

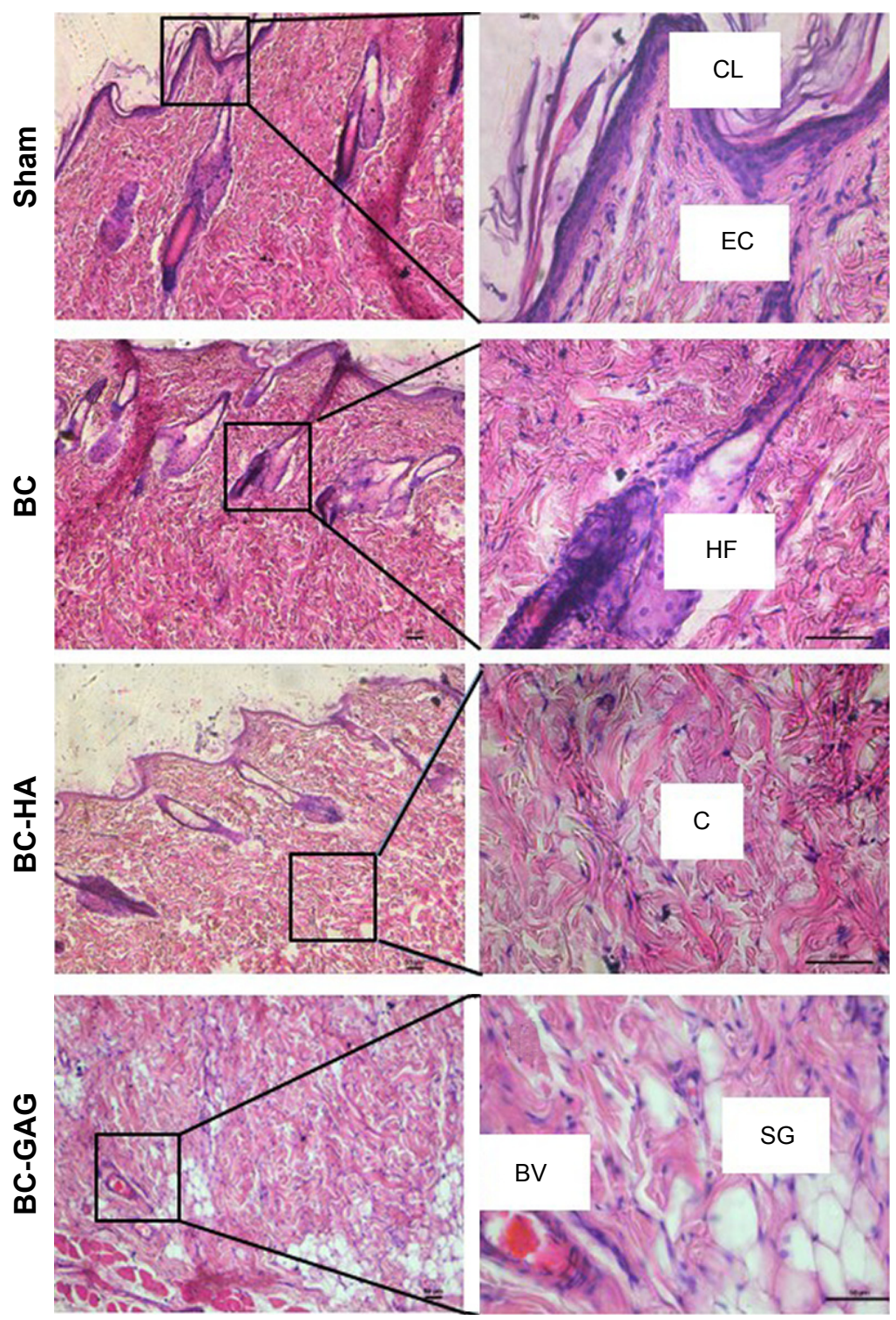

Figure S4 Hematoxylin-and-eosin-stained histological sections of rat's skin of nearby implanted scaffolds. Left and right panels show images at I0x and 40x, respectively. Note: Scale bars in left panels are 50 um and right panels are 100 um.

Abbreviations: BC, bacterial cellulose; BC-GAG, BC-glycosaminoglycans; BC-HA, Bc-hydroxyapatite; BV, blood vessel; C, collagen fibers; CL, cornified layer; EC, squamous epithelial cells; HF, hair follicle; SG, sebaceous gland.

International Journal of Nanomedicine

\section{Publish your work in this journal}

The International Journal of Nanomedicine is an international, peerreviewed journal focusing on the application of nanotechnology in diagnostics, therapeutics, and drug delivery systems throughou the biomedical field. This journal is indexed on PubMed Central,

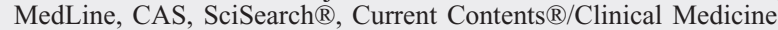

\section{Dovepress}

Journal Citation Reports/Science Edition, EMBase, Scopus and the Elsevier Bibliographic databases. The manuscript management system is completely online and includes a very quick and fair peer-review system, which is all easy to use. Visit http://www.dovepress.com/ testimonials.php to read real quotes from published authors. 